\title{
A review of turbulence measurements using ground-based wind lidars
}

\author{
A. Sathe and J. Mann \\ DTU Wind Energy, Ris $\emptyset$ campus, Roskilde, Denmark
}

Correspondence to: A. Sathe (amsat@dtu.dk)

Received: 29 May 2013 - Published in Atmos. Meas. Tech. Discuss.: 26 July 2013

Revised: 7 October 2013 - Accepted: 16 October 2013 - Published: 19 November 2013

\begin{abstract}
A review of turbulence measurements using ground-based wind lidars is carried out. Works performed in the last $30 \mathrm{yr}$, i.e., from 1972-2012 are analyzed. More than $80 \%$ of the work has been carried out in the last $15 \mathrm{yr}$, i.e., from 1997-2012. New algorithms to process the raw lidar data were pioneered in the first 15 yr, i.e., from 19721997, when standard techniques could not be used to measure turbulence. Obtaining unfiltered turbulence statistics from the large probe volume of the lidars has been and still remains the most challenging aspect. Until now, most of the processing algorithms that have been developed have shown that by combining an isotropic turbulence model with raw lidar measurements, we can obtain unfiltered statistics. We believe that an anisotropic turbulence model will provide a more realistic measure of turbulence statistics. Future development in algorithms will depend on whether the unfiltered statistics can be obtained without the aid of any turbulence model. With the tremendous growth of the wind energy sector, we expect that lidars will be used for turbulence measurements much more than ever before.
\end{abstract}

\section{Introduction}

This study is motivated by the recent increase in the use of wind lidars for wind energy purposes. Understanding and measuring atmospheric turbulence is vital to efficient harnessing of wind energy and to measuring the structural integrity of a wind turbine. Traditionally, meteorological mast (met-mast) anemometry has been used; in this method, either cup or sonic anemometers are mounted on slender booms at one or several heights to measure turbulence over a certain period of time. For wind energy purposes, much interest is focused on the turbulence of the wind and temperature, although some attention is also paid to other atmospheric variables such as pressure, humidity, density, etc. In this article we focus our review only on the measurement of atmospheric turbulence of wind by ground-based wind lidars. To our knowledge, there is no review article dedicated to such a topic. Engelbart et al. (2007) provide an overall review of different remote sensing techniques for turbulence measurements including lidars, whereas Emeis et al. (2007) provide a review of the use of lidars for wind energy applications without focusing in particular on turbulence measurements.

Turbulence affects the wind turbines mainly in two ways: first, the fluctuations that are caused in the extracted wind power (Kaiser et al., 2007; Gottschall and Peinke, 2008), and second, the fluctuations in the loads on different components of a wind turbine (Sathe et al., 2012). These fluctuations result in inefficient harnessing of wind energy and have the potential to inflict fatigue damage. Wind turbines are generally designed for a period of twenty years (Burton et al., 2001; IEC, 2005a). The size of a wind turbine has grown significantly over the past few decades. The upper tip of a modern wind turbine blade can easily reach heights up to $200 \mathrm{~m}$ above the ground. Thus measuring and understanding the turbulent wind field at great heights is essential. It is very expensive to install and operate a met-mast at such great heights for a sustained period of time. Especially offshore, the costs increase significantly owing to the large foundation needed to support the met-mast. Moreover, a met-mast cannot be moved from one place to another, thus limiting the physical range of the studies. Because of all these factors, measuring in the wake of a wind turbine (or multiple wakes) becomes quite a challenge. Lidars have the potential to counter these disadvantages of the met-mast anemometry. 
Recently, lidars have been used extensively for the measurement of the mean wind speed and wind profiling (Smith et al., 2006; Kindler et al., 2007; Peña et al., 2009; Wagner et al., 2011). However, despite having been researched for years all over the world (particularly for meteorological studies), they have not yet been accepted for turbulence measurements. Lidars' lack of acceptance can be attributed to different reasons, such as large measurement volumes leading to spatial averaging of turbulence along the line-of-sight of its measurement axis, cross-contamination by different components of the wind field, low sampling rates, etc.

This article attempts to answer two research questions pertaining to measurement of atmospheric turbulence by ground-based wind lidars:

1. What is the state of the art?

2. Are further improvements needed, either in lidar technology or in data-processing algorithms that can make turbulence measurements more reliable?

It is to be noted that our main focus is on reviewing processing algorithms that use raw lidar data and different scanning configurations. Although it is known that different lidar parameters can also influence turbulence measurements (Frehlich, 1994; Banakh and Werner, 2005), we do not carry out a review with respect to the technology itself, but that can be found in Hardesty and Darby (2005) to a certain extent.

In general, for any variable (or a combination of different variables) turbulence is characterized in several ways: in the time domain, as auto- or cross-correlation functions, turbulent kinetic energy dissipation rates, and structure functions; or in the Fourier space, as one- or multi-dimensional auto- or cross-spectrum. In the remainder of this article, we will delve into these aspects in some detail. We believe that writing such a review article without including any mathematics will provide only a superficial explanation. Hence we have included some mathematics using a uniform set of notations in order to provide a clear perspective of the past studies. To this end we define some mathematical preliminaries that characterize atmospheric turbulence in Sect. 2. In Sect. 3, we provide some explanation of the standard scanning configurations that have been used in the past. Section 4 attempts to answer the first research question posed above. It is divided into two subsections, in which we first describe the pioneering works along with the corresponding mathematics, and then we classify the past studies based on the investigated turbulence parameters. Readers who are interested only in knowing the state of the art without going into too much mathematical details can directly jump to Sect. 4.2. In Sect. 5, some perspectives are provided on the specific turbulence parameters that are useful for wind energy purposes. A summary is provided in Sect. 6, in which we attempt to answer the second research question posed above.

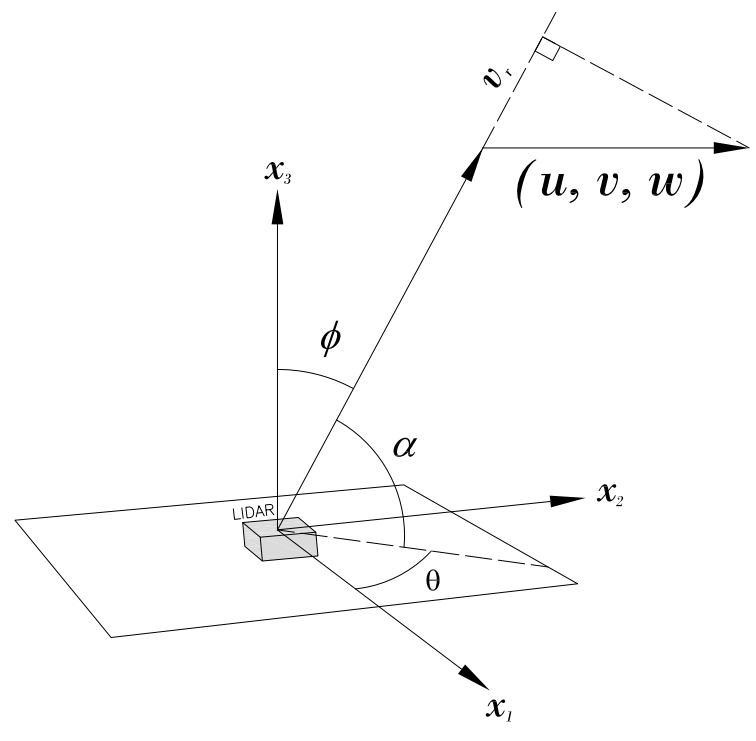

Fig. 1. Schematic of the lidar operating in a staring mode.

\section{Mathematical preliminaries}

In this article we will often switch between the boldfaced vector notation and the Einstein indicial notation. We define the wind field as $\boldsymbol{v}=(u, v, w)$, where we define the coordinate system to be right-handed such that $u$ (longitudinal component) is in the $x_{1}$ direction, $v$ (transversal component) is in the $x_{2}$ direction, and $w$ is in the vertical $x_{3}$ direction (see Fig. 1). If we consider that the fluctuations of the wind field are homogeneous in space then the auto- or cross-covariance functions can be defined only in terms of the separation distance as

$R_{i j}(\boldsymbol{r})=\left\langle v_{i}^{\prime}(\boldsymbol{x}) v_{j}^{\prime}(\boldsymbol{x}+\boldsymbol{r})\right\rangle$,

where $R_{i j}(\boldsymbol{r})$ is the auto- or cross-covariance function, $i, j=(1,2,3)$ are the indices corresponding to the components of the wind field, $\boldsymbol{x}$ is the position vector in the threedimensional Cartesian coordinate system, $\boldsymbol{r}=\left(r_{1}, r_{2}, r_{3}\right)$ is the separation vector, \langle\rangle denotes ensemble averaging, and ' denotes fluctuations around the ensemble average. Equation (1) denotes a two-point turbulent statistic. At $\mathbf{r}=0$ we get a single-point turbulent statistic, which we can denote as the variances and covariances. In matrix form it can be written as

$\mathbf{R}=\left[\begin{array}{ccc}\left\langle u^{\prime 2}\right\rangle & \left\langle u^{\prime} v^{\prime}\right\rangle & \left\langle u^{\prime} w^{\prime}\right\rangle \\ \left\langle v^{\prime} u^{\prime}\right\rangle & \left\langle v^{\prime 2}\right\rangle & \left\langle v^{\prime} w^{\prime}\right\rangle \\ \left\langle w^{\prime} u^{\prime}\right\rangle & \left\langle w^{\prime} v^{\prime}\right\rangle & \left\langle w^{\prime 2}\right\rangle\end{array}\right]$,

where the diagonal terms are the variances of the respective wind field components and the off-diagonal terms are the covariances. Here, it is implied that $\mathbf{R}=\mathbf{R}(0)$, and we drop the argument and the bracket for simplicity. From the definition 
of $\mathbf{R}(\boldsymbol{r})$ and $\mathbf{R}$, we can define integral length scale as

$\ell_{i j}=\frac{1}{R_{i j}} \int_{0}^{\infty} R_{i j}\left(r_{1}\right) \mathrm{d} r_{1}$.

Similar to $R_{i j}(\boldsymbol{r})$, another useful two-point statistic to characterize turbulence is the velocity structure function, which is defined as

$D_{i j}(\boldsymbol{r})=\left\langle\left(v_{i}^{\prime}(\boldsymbol{x}+\boldsymbol{r})-v_{i}^{\prime}(\boldsymbol{x})\right)\left(v_{j}^{\prime}(\boldsymbol{x}+\boldsymbol{r})-v_{j}^{\prime}(\boldsymbol{x})\right)\right\rangle$.

On many occasions it convenient to study turbulence in the Fourier domain instead of the time domain. To this extent, we can define the spectral velocity tensor (or the threedimensional spectral density) as the Fourier transform of $R_{i j}(\boldsymbol{r})$,

$\Phi_{i j}(\boldsymbol{k})=\frac{1}{(2 \pi)^{3}} \int R_{i j}(\boldsymbol{r}) \exp (\mathrm{i} \boldsymbol{k} \cdot \boldsymbol{r}) \mathrm{d} \boldsymbol{k}$,

where $\Phi_{i j}(\boldsymbol{k})$ is the three-dimensional spectral velocity tensor, $\boldsymbol{k}=\left(k_{1}, k_{2}, k_{3}\right)$ is the wave vector, and $\int \mathrm{d} \boldsymbol{k}=$ $\int_{-\infty}^{\infty} \int_{-\infty}^{\infty} \int_{-\infty}^{\infty} \mathrm{d} k_{1} \mathrm{~d} k_{2} \mathrm{~d} k_{3}$. From Eq. (5), it is obvious that $R_{i j}(\boldsymbol{r})$ is the inverse Fourier transform of $\Phi_{i j}(\boldsymbol{k})$. Practically, it is not possible to measure a spectral velocity tensor, since we would need measurements at all points in a threedimensional space. A one-dimensional velocity spectrum is then used, which is defined as

$$
\begin{aligned}
F_{i j}\left(k_{1}\right) & =\frac{1}{2 \pi} \int_{-\infty}^{\infty} R_{i j}\left(r_{1}\right) \exp \left(-\mathrm{i} k_{1} r_{1}\right) \mathrm{d} r_{1} \\
& =\int_{-\infty}^{\infty} \int_{-\infty}^{\infty} \Phi_{i j}(\boldsymbol{k}) \mathrm{d} k_{2} \mathrm{~d} k_{3} .
\end{aligned}
$$

Another important statistic in the Fourier domain is the coherence function defined as

$\operatorname{coh}_{i j}\left(k_{1}\right)=\frac{\left|\chi_{i j}\left(k_{1}, r_{2}, r_{3}\right)\right|^{2}}{F_{i i}\left(k_{1}\right) F_{j j}\left(k_{1}\right)}$

where $\chi_{i j}\left(k_{1}, r_{2}, r_{3}\right)$ denotes the cross spectra between the components $i$ and $j$, and $F_{i i}\left(k_{1}\right)=\chi_{i i}\left(k_{1}, 0,0\right)$ and $F_{j j}\left(k_{1}\right)=\chi_{j j}\left(k_{1}, 0,0\right)$ (no summation over repeated indices) are the one-dimensional spectra of the $i$ and $j$ components, respectively.

Ideally, we would like to measure one or more of the quantities in Eqs. (1)-(8) using a lidar. However, owing to inherent difficulties in the lidar systems, this is quite often impossible. We then have to resort to combining lidar measurements with simplified turbulence models that are functions of several variables. As an example, according to Mann (1994), the turbulence structure in the neutral atmospheric surface layer described by $\Phi_{i j}(\boldsymbol{k})$ can be modeled as a function of only three parameters, $C \varepsilon^{2 / 3}$ (which is a product of the universal Kolmogorov constant $C \approx 1.5$ (Pope, 2000) and the turbulent kinetic energy dissipation rate to the two-third power $\varepsilon^{2 / 3}$ ), a characteristic length scale, and an anisotropy parameter. Many studies in the past have attempted to estimate $\varepsilon$ from the lidar measurements. Thus, measurement of one or more of the model parameters using lidars is also a significant contribution to the measurement of turbulence.

\section{Lidar measurement configurations}

A lidar is an acronym for light detection and ranging, and some fundamentals of its working can be found in Measures (1984). Most of the past studies have used one of the following three measurement configurations:

1. Staring mode - the lidar beam is fixed at a certain angle with respect to the vertical axis.

2. Scanning mode in a cone - this is called the velocity azimuth display (VAD, also called the plan position indicator, PPI) technique.

3. Scanning mode in a vertical plane - this is called the range height indicator (RHI) scanning technique.

\subsection{Staring mode}

Figure 1 shows the schematic of a lidar operating in staring mode. At a given instant of time - if we assume that a lidar measures at a point, and that the lidar beam is inclined at a certain angle $\phi$ (in some literature the complement of $\phi$ is used, which is called the elevation angle $\alpha=90^{\circ}-\phi$ ) from the vertical axis, and makes an azimuth angle $\theta$ with respect to the $x_{1}$ axis in the horizontal plane - then the radial velocity (also called the line-of-sight velocity) can be mathematically written as

$v_{\mathrm{r}}\left(\phi, \theta, d_{\mathrm{f}}\right)=\boldsymbol{n}(\phi, \theta) \cdot \boldsymbol{v}\left(\boldsymbol{n}(\phi, \theta) d_{\mathrm{f}}\right)$,

where $v_{\mathrm{r}}$ is the radial velocity measured at a point, $\boldsymbol{n}=$ $(\cos \theta \sin \phi, \sin \theta \sin \phi, \cos \phi)$ is the unit directional vector for a given $\phi$ and $\theta$, and $d_{\mathrm{f}}$ is the distance from the lidar at which the measurement is obtained. In Eq. (9), we have implicitly assumed that $v_{\mathrm{r}}$ is positive for the wind going away from the lidar axis, the coordinate system is right-handed, and $u$ is aligned with the $x_{1}$ axis in a horizontal plane. In reality, a lidar never receives backscatter from exactly one point, but rather from all over the physical space. Fortunately the transverse dimensions of a lidar beam is much smaller than the longitudinal dimensional, and for all practical purposes we can consider the backscatter to be received only along the lidar beam axis. We can then mathematically represent the radial velocity as the convolved signal,

$\tilde{v}_{\mathrm{r}}\left(\phi, \theta, d_{\mathrm{f}}\right)=\int_{-\infty}^{\infty} \varphi(s) \boldsymbol{n}(\phi, \theta) \cdot \boldsymbol{v}\left(\boldsymbol{n}(\phi, \theta)\left(d_{\mathrm{f}}+s\right)\right) \mathrm{d} s$, 


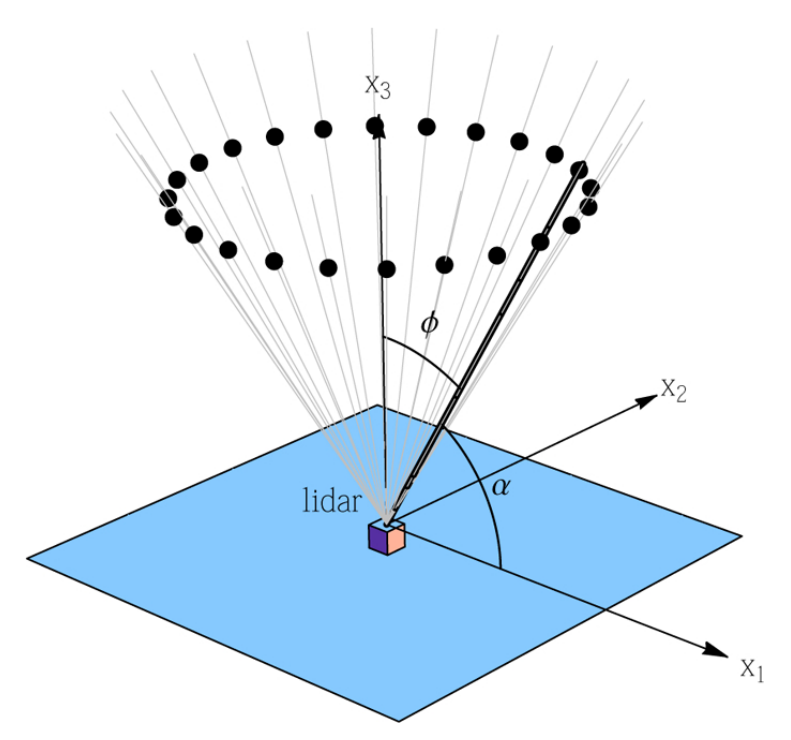

Fig. 2. Schematic of the lidar operating in a VAD scanning mode.

where $\tilde{v}_{\mathrm{r}}$ is the weighted average radial velocity, $\varphi(s)$ is any weighting function integrating to one (that depends on the whether the type of lidar being used is a continuous-wave (C-W) or a pulsed lidar), and $s$ is the distance along the beam from the measurement point of interest.

\subsection{VAD technique}

Figure 2 shows the schematic of the VAD scanning technique. It is an extension of a staring mode, where the lidar beam rotates around a vertical axis, thus forming a cone with the base at the measurement distance of interest and the apex at the lidar source. $v_{\mathrm{r}}$ is thus measured at different $\theta$, and $\phi$ is kept constant throughout the scan. At a given $d_{\mathrm{f}}$, the radial velocity can be written as

$v_{\mathrm{r}}(\theta)=u \cos \theta \sin \phi+v \sin \theta \sin \phi+w \cos \phi$.

From Eq. (11), we see that when $\phi, \theta$ and $d_{\mathrm{f}}$ are known, $v_{\mathrm{r}}$ is only a function of three unknown wind field components, i.e., $u, v$ and $w$. In principle, we then need three measurements of $\tilde{v}_{\mathrm{r}}$ at three different $\theta$ to deduce the $u, v$ and $w$ components. For a standard VAD scan, we normally have much more than three measurements along the azimuth circle. We thus have more equations and only three unknowns, if we assume horizontal homogeneity. Least squares analysis can be used to deduce the three unknown wind field components.

\subsection{RHI technique}

Figure 3 shows the schematic of the RHI scanning technique. It is also an extension of staring mode, where the lidar beam rotates in a vertical plane at different $\phi$, and $\theta$ is kept constant throughout the scan. We can use the same Eq. (11) by varying $\phi$ and keeping $\theta$ constant to deduce the wind field

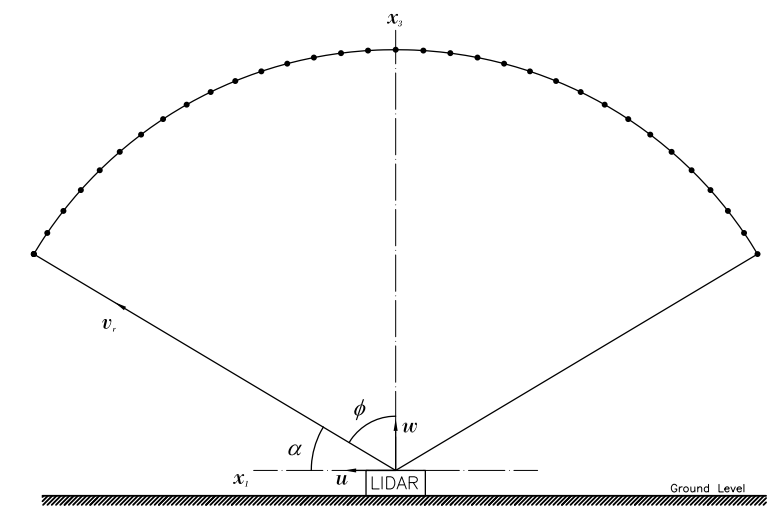

Fig. 3. Schematic of the lidar operating in a RHI scanning mode.

components. Actually, from a single RHI scan, only two velocity components can be deduced, namely the vertical and the horizontal in the plane of the RHI scan. If $\theta=0$ is kept constant, then the $v$ component cannot be determined (see Eq. 11). Owing to the fact that the lidar is placed on solid ground, $\phi$ can vary only between $0^{\circ}$ and $180^{\circ}$ in a vertical plane. Usually, the scanning plane is aligned such that it is in the mean wind direction. As in the VAD technique, if we then have more measurements at different $\phi$, the three unknown wind field components are estimated using the least squares analysis.

\section{State of the art in turbulence measurements using ground-based lidars}

Generally, measurement of atmospheric turbulence is a very challenging prospect. With traditional instruments such as the cup/sonic anemometers, great care has to be taken with regards to sampling frequencies, averaging periods, correction for flow distortions, and orientation of the instrument. Because these instruments essentially measure at a point, deducing turbulence information from the raw data can be carried out using the standard procedures if these instruments are properly set up (Kaimal and Finnigan, 1994). Due to the fact that lidars measure in a much larger volume, and at different points in space, standard techniques do not suffice even if the instrument is correctly set up. Deducing turbulence information from the raw lidar data has been and remains the most challenging aspect. In the following sections, we first discuss the pioneering works that have demonstrated some of the techniques to process the raw lidar data in order to measure turbulence; this is followed by a discussion of recent studies that have used some of these techniques.

\subsection{Pioneering works}

Although much of the lidar turbulence work has been carried out using the scanning configurations described in Sect. 3, the ideas were taken from the pioneering works on radar me- 
teorology (Lhermitte, 1962; Browning and Wexler, 1968). Discussing a bit of mathematics from the radar studies is essential, since they can and have been used in lidar studies too. Lhermitte (1962) was one of the first to explain the VAD scanning technique using Doppler radars, where $v_{\mathrm{r}}$ is mathematically represented as linear combination of the sine and cosine functions of $\theta$. Browning and Wexler (1968) were the first to conduct an experiment with a pulsed Doppler radar and estimate the $u$ and $v$ components of the wind field along with the mean horizontal divergence, stretching and shearing deformation, in the height range of $1.5-6 \mathrm{~km}$. The latter terms were obtained using a Taylor series expansion around the center of a scanning circle. An error analysis was also carried out to limit the errors in the estimated quantities below a certain level, which led to limiting the values of $\phi$. The radar-estimated quantities were however not compared with any reference instrument. Based on the VAD scanning, Lhermitte (1969) then suggested a technique of estimating turbulence components $R_{i j}$ that was based on the measurements of the variance of the radial velocity $\left\langle v_{\mathrm{r}}^{\prime 2}\right\rangle$. Mathematically, by substituting the definition of $\boldsymbol{n}(\phi, \theta)$ into Eq. (11), and by squaring and ensemble-averaging, we get

$\left\langle v_{\mathrm{r}}^{\prime 2}\right\rangle=\left\langle u^{\prime 2}\right\rangle \sin ^{2} \phi \cos ^{2} \theta+\left\langle v^{\prime 2}\right\rangle \sin ^{2} \phi \sin ^{2} \theta+\left\langle w^{\prime 2}\right\rangle \cos ^{2} \phi$

$+2\left\langle u^{\prime} v^{\prime}\right\rangle \sin ^{2} \phi \sin \theta \cos \theta+2\left\langle u^{\prime} w^{\prime}\right\rangle \sin \phi \cos \phi \cos \theta$

$+2\left\langle v^{\prime} w^{\prime}\right\rangle \sin \phi \cos \phi \sin \theta$.

For ease of reading, we do not include the functional dependence of $v_{\mathrm{r}}$ on $\phi, \theta$ and $d_{\mathrm{f}}$, but it is implicitly assumed. Wilson (1970) was the first to conduct an experiment using a pulsed Doppler radar and estimate $R_{i j}$ from the $\left\langle v_{\mathrm{r}}^{\prime 2}\right\rangle$ data in the convective boundary layer $(0.1-1.3 \mathrm{~km})$. Only turbulence scales larger than the pulse volume but smaller than the scanning circle could be measured since all the data from a single scan was used. Also, no comparison with measurements from a reference instrument was carried out, and hence the reliability of the radar measurements could not be verified. Wilson (1970) demonstrated a mathematically equivalent way of performing the Fourier analysis where integrals were defined in four quadrants as

$I_{n}=\int_{(n-1) \pi / 2}^{n \pi / 2}\left\langle v_{\mathrm{r}}^{\prime 2}\right\rangle \mathrm{d} \theta$,

where $n=1, \ldots, 4$. By combining these integrals he then obtained the following expressions:

$$
\begin{aligned}
& \sin ^{2} \phi\left(\left\langle u^{\prime 2}\right\rangle+\left\langle v^{\prime 2}\right\rangle+\frac{2\left\langle w^{\prime 2}\right\rangle}{\tan ^{2} \phi}\right)=\frac{1}{\pi}\left(I_{1}+I_{2}+I_{3}+I_{4}\right), \\
& \left\langle u^{\prime} w^{\prime}\right\rangle \sin 2 \phi=\frac{1}{4}\left(\left(I_{1}+I_{2}\right)-\left(I_{3}+I_{4}\right)\right),
\end{aligned}
$$

$$
\begin{aligned}
\left\langle v^{\prime} w^{\prime}\right\rangle \sin 2 \phi & =\frac{1}{4}\left(\left(I_{1}+I_{4}\right)-\left(I_{2}+I_{3}\right)\right), \\
\left\langle u^{\prime} v^{\prime}\right\rangle \sin ^{2} \phi & =\frac{1}{4}\left(\left(I_{1}+I_{3}\right)-\left(I_{2}+I_{4}\right)\right) .
\end{aligned}
$$

Using this method, we can thus estimate the covariances of $\mathbf{R}$ at a given $\phi$. The Wilson (1970) method was extended by Kropfli (1986) to also include the turbulence scales larger than the scanning circle by using the data from multiple scans. Although the method was developed for Doppler radar studies, it could also be used for Doppler lidar studies.

One of the first lidar studies to measure the $u$ spectrum using a $\mathrm{C}-\mathrm{W}$ Doppler $\mathrm{CO}_{2}$ lidar was carried out by Lawrence et al. (1972). The lidar was oriented in the mean wind direction and the measurements were performed at $10 \mathrm{~m}$ above the ground, where the probe volume length (also called the full width half maximum $(\mathrm{FWHM})=2 l$ ) of the weighting function $\varphi(s)$ was about $30 \mathrm{~cm}$. They concluded that the lidar measurements of the $u$ spectra were considerably better than those obtained using a cup anemometer. In this case $\left\langle u^{\prime 2}\right\rangle$ can be computed directly from the $u$ fluctuations, since the lidar beam is oriented in the mean wind direction, and the probe volume is quite small. The aforementioned studies were based on detecting the Doppler shift in the frequency of the reflected radiation. Using a non-Doppler effect technique, Kunkel et al. (1980) was one of the first to estimate $\left\langle u^{\prime 2}\right\rangle$ using cross-correlation analysis and an aerosol lidar. The lidar beams were scanned in a sequence of three azimuth angles. Turbulence was assumed to be isotropic and the velocity fluctuations were assumed to have a Gaussian distribution. The lidar-derived variances compared well with the variances measured by a reference instrument mounted on a tower at $70 \mathrm{~m}$. A technique was also demonstrated to estimate $\varepsilon$ from the lidar data; this requires measurements of the boundary layer height $z_{i},\left\langle u^{\prime 2}\right\rangle$ and the radial velocity spectrum. Kunkel et al. (1980) estimated $z_{i}$ using the lidar spectrum observations. As mentioned in Seibert et al. (2000), $z_{i}$ measurements are subjected to significant uncertainties; hence, one should be careful in using this method to estimate $\varepsilon$ from the lidar data. Hardesty et al. (1982) was one of the first to measure the $u$ spectrum in the rotating plane of a wind turbine of about $20 \mathrm{~m}$ diameter. A C-W lidar was placed on a ground and a rotating mirror was mounted on a meteorological tower such that the laser beam directed towards the mirror would focus the beam in a vertical plane at a certain $\phi$. Due to the rotating action, VAD scanning was performed in a vertical plane. Taylor series expansion around the center of a scanning circle is then used for the $u$ component, so that the gradients in the vertical and horizontal directions are removed. Owing to the small half-opening angles, the contributions by the cross components of $R_{i j}$ were assumed negligible. One has to be careful in using this assumption, as has been explained in detail by Sathe et al. (2011b).

Extending the work of Wilson (1970), Eberhard et al. (1989) derived a new set of equations to 
estimate $R_{i j}$ from the lidar data using VAD scanning, and they termed their method the partial Fourier decomposition technique (the same name can also be used for the Wilson, 1970 method). By using standard trigonometric identities, they rearranged Eq. (12) as

$$
\begin{aligned}
& \left\langle v_{\mathrm{r}}^{\prime 2}\right\rangle=\frac{\sin ^{2} \phi}{2}\left(\left\langle u^{\prime 2}\right\rangle+\left\langle v^{\prime 2}\right\rangle+\frac{2\left\langle w^{\prime 2}\right\rangle}{\tan ^{2} \phi}\right) \\
& +\left\langle u^{\prime} w^{\prime}\right\rangle \sin 2 \phi \cos \theta+\left\langle v^{\prime} w^{\prime}\right\rangle \sin 2 \phi \sin \theta \\
& +\frac{\sin ^{2} \phi}{2}\left(\left\langle u^{\prime 2}\right\rangle-\left\langle v^{\prime 2}\right\rangle\right) \cos 2 \theta+\left\langle u^{\prime} v^{\prime}\right\rangle \sin ^{2} \phi \sin 2 \theta .
\end{aligned}
$$

If we denote Eq. (18) as a Fourier series with the corresponding Fourier coefficients, we then have

$$
\begin{aligned}
& \frac{\sin ^{2} \phi}{2}\left(\left\langle u^{\prime 2}\right\rangle+\left\langle v^{\prime 2}\right\rangle+\frac{2\left\langle w^{\prime 2}\right\rangle}{\tan ^{2} \phi}\right)=\frac{a_{0}}{2}=\frac{1}{2 \pi} \int_{0}^{2 \pi}\left\langle v_{\mathrm{r}}^{\prime 2}\right\rangle \mathrm{d} \theta, \\
& \left\langle u^{\prime} w^{\prime}\right\rangle \sin 2 \phi=a_{1}=\frac{1}{\pi} \int_{0}^{2 \pi}\left\langle v_{\mathrm{r}}^{\prime 2}\right\rangle \cos \theta \mathrm{d} \theta, \\
& \left\langle v^{\prime} w^{\prime}\right\rangle \sin 2 \phi=b_{1}=\frac{1}{\pi} \int_{0}^{2 \pi}\left\langle v_{\mathrm{r}}^{\prime 2}\right\rangle \sin \theta \mathrm{d} \theta, \\
& \frac{\sin ^{2} \phi}{2}\left(\left\langle u^{\prime 2}\right\rangle-\left\langle v^{\prime 2}\right\rangle\right)=a_{2}=\frac{1}{\pi} \int_{0}^{2 \pi}\left\langle v_{\mathrm{r}}^{\prime 2}\right\rangle \cos 2 \theta \mathrm{d} \theta, \\
& \left\langle u^{\prime} v^{\prime}\right\rangle \sin ^{2} \phi=b_{2}=\frac{1}{\pi} \int_{0}^{2 \pi}\left\langle v_{\mathrm{r}}^{\prime 2}\right\rangle \sin 2 \theta \mathrm{d} \theta,
\end{aligned}
$$

where $a_{0}$ is the average, $a_{1}$ and $a_{2}$ are the Fourier cosines, and $b_{1}$ and $b_{2}$ are the Fourier sine coefficients. As an example, say for a given $30 \mathrm{~min}$ time series, if we have several measurements of $v_{\mathrm{r}}$ at each $\theta$, then $\left\langle v_{\mathrm{r}}^{\prime 2}\right\rangle$ can then be computed for each $\theta$, and hence so can the corresponding Fourier coefficients. At one half-opening angle, we can thus compute the off-diagonal terms of Eq. (2), i.e., covariances. By measuring at two half-opening angles, and combining Eqs. (19) and (22), we can also compute the variances. As with the Wilson (1970) method, no reference instrument was available to verify the reliability of the measurements. Nevertheless, the study was valuable as the method can potentially be used with the current lidar systems at those sites where the reference measurements are available.

In all of the above studies with a Doppler lidar (or radar), horizontal homogeneity is a key assumption that makes it possible to combine lidar beam measurements from different points in space and obtain turbulence statistics. This limits the application of such studies to homogeneous flat terrains. Frisch (1991) performed pioneering work on extending the analysis of Wilson (1970) and Eberhard et al. (1989) to also include horizontal inhomogeneities in the turbulence mea- surements. He mathematically demonstrated that, by measuring at three half-opening angles, we can compute $R_{i j}$ using the VAD scanning without assuming horizontal homogeneity. This could potentially have huge implications on turbulence measurements in complex (non-homogeneous) terrain, where wind turbines are subjected to large turbulent forces. Using the Taylor series expansion around the center of a scanning circle, Frisch (1991) denoted $\left\langle v_{\mathrm{r}}^{\prime 2}\right\rangle$ as a Fourier series up to the third harmonic. For each $\phi$ we then obtain a set of Fourier coefficients; i.e., for $\phi=\phi_{1}$ we obtain $a_{01}$ as the Fourier coefficient of the zeroth harmonic, $a_{11}$ and $b_{11}$ as the Fourier coefficients of the first harmonic, $a_{21}, b_{21}$ as the Fourier coefficient of the second harmonic, and $a_{31}$ and $b_{31}$ as the Fourier coefficients of the third harmonic. Similarly, we obtain the Fourier coefficients at $\phi=\phi_{2}$ and $\phi=\phi_{3}$. The second index in the subscript of the Fourier coefficients denotes the measurement at the corresponding $\phi$. To compute $R_{i j}$, we only need the Fourier coefficients from the zeroth up to the second harmonic given by Eqs. (19)-(23). The corresponding expressions for the components of $R_{i j}$ are then given as follows.

$$
\begin{aligned}
& \left\langle u^{\prime 2}\right\rangle=t_{1}+t_{2}, \\
& \left\langle v^{\prime 2}\right\rangle=t_{1}-t_{2},
\end{aligned}
$$

where

$$
\begin{aligned}
& t_{1}=\left(a_{01} \cos \left(\phi_{3}\right)\left(\sin \left(\phi_{2}\right) \sin \left(2 \phi_{2}\right) \cos \left(\phi_{3}\right)-2 \sin ^{2}\left(\phi_{3}\right) \cos ^{2}\left(\phi_{2}\right)\right)\right. \\
& +a_{02} \cos \left(\phi_{1}\right)\left(\sin \left(\phi_{3}\right) \sin \left(2 \phi_{3}\right) \cos \left(\phi_{1}\right)-2 \sin ^{2}\left(\phi_{1}\right) \cos ^{2}\left(\phi_{3}\right)\right) \\
& \left.+a_{03} \cos \left(\phi_{2}\right)\left(\sin \left(\phi_{1}\right) \sin \left(2 \phi_{1}\right) \cos \left(\phi_{2}\right)-2 \sin ^{2}\left(\phi_{2}\right) \cos ^{2}\left(\phi_{1}\right)\right)\right) \\
& /\left(2 \sin ^{2}\left(\phi_{1}\right) \sin ^{2}\left(\phi_{2}\right)\left(\cos \left(\phi_{2}\right)-\cos \left(\phi_{1}\right)\right) \cos ^{2}\left(\phi_{3}\right)\right. \\
& +2 \sin ^{2}\left(\phi_{3}\right)\left(\sin ^{2}\left(\phi_{1}\right) \cos ^{2}\left(\phi_{2}\right)\left(\cos \left(\phi_{1}\right)-\cos \left(\phi_{3}\right)\right)\right. \\
& \left.\left.+\sin ^{2}\left(\phi_{2}\right) \cos ^{2}\left(\phi_{1}\right)\left(\cos \left(\phi_{3}\right)-\cos \left(\phi_{2}\right)\right)\right)\right) \\
& t_{2}=\frac{a_{22} \cos \left(\phi_{1}\right) \csc ^{2}\left(\phi_{2}\right)-a_{21} \cos \left(\phi_{2}\right) \csc ^{2}\left(\phi_{1}\right)}{\cos \left(\phi_{1}\right)-\cos \left(\phi_{2}\right)} \\
& \left\langle w^{\prime 2}\right\rangle=\left(a_{01} \sin ^{2}\left(\phi_{2}\right) \sin ^{2}\left(\phi_{3}\right)\left(\cos \left(\phi_{2}\right)-\cos \left(\phi_{3}\right)\right)\right. \\
& +\sin ^{2}\left(\phi_{1}\right)\left(a_{02} \sin ^{2}\left(\phi_{3}\right)\left(\cos \left(\phi_{3}\right)-\cos \left(\phi_{1}\right)\right)\right. \\
& \left.\left.+a_{03} \sin ^{2}\left(\phi_{2}\right)\left(\cos \left(\phi_{1}\right)-\cos \left(\phi_{2}\right)\right)\right)\right) \\
& /\left(\sin ^{2}\left(\phi_{1}\right) \sin ^{2}\left(\phi_{2}\right)\left(\cos \left(\phi_{1}\right)-\cos \left(\phi_{2}\right)\right) \cos ^{2}\left(\phi_{3}\right)\right. \\
& +\sin ^{2}\left(\phi_{3}\right)\left(\sin ^{2}\left(\phi_{1}\right) \cos { }^{2}\left(\phi_{2}\right)\left(\cos \left(\phi_{3}\right)-\cos \left(\phi_{1}\right)\right)\right. \\
& \left.\left.+\sin ^{2}\left(\phi_{2}\right) \cos ^{2}\left(\phi_{1}\right)\left(\cos \left(\phi_{2}\right)-\cos \left(\phi_{3}\right)\right)\right)\right)
\end{aligned}
$$




$$
\begin{aligned}
\left\langle u^{\prime} w^{\prime}\right\rangle & =\frac{a_{11} m_{1}+a_{12} m_{2}+a_{13} m_{3}}{\Delta}, \\
\left\langle v^{\prime} w^{\prime}\right\rangle & =\frac{b_{11} m_{1}+b_{12} m_{2}+b_{13} m_{3}}{\Delta},
\end{aligned}
$$

where

$$
\begin{aligned}
& m_{1}=\sin \left(\phi_{2}\right) \sin \left(\phi_{3}\right)\left(\cos \left(2 \phi_{3}\right)-\cos \left(2 \phi_{2}\right)\right), \\
& m_{2}=\frac{1}{2}\left(\sin \left(3 \phi_{1}\right) \sin \left(\phi_{3}\right)-\sin \left(\phi_{1}\right) \sin \left(3 \phi_{3}\right)\right), \\
& m_{3}=\sin \left(\phi_{1}\right) \sin \left(\phi_{2}\right)\left(\cos \left(2 \phi_{2}\right)-\cos \left(2 \phi_{1}\right)\right), \\
& \Delta=2 \sin ^{3}\left(\phi_{3}\right)\left(\sin \left(\phi_{1}\right) \sin \left(2 \phi_{2}\right) \cos ^{2}\left(\phi_{1}\right)-\right. \\
& \left.\sin \left(2 \phi_{1}\right) \sin \left(\phi_{2}\right) \cos ^{2}\left(\phi_{2}\right)\right) \\
& +2\left(\sin \left(2 \phi_{1}\right) \sin ^{3}\left(\phi_{2}\right)-\sin ^{3}\left(\phi_{1}\right) \sin \left(2 \phi_{2}\right)\right) \sin \left(\phi_{3}\right) \cos ^{2}\left(\phi_{3}\right) \\
& +\sin \left(\phi_{1}\right) \sin \left(\phi_{2}\right) \sin \left(2 \phi_{3}\right)\left(\cos \left(2 \phi_{2}\right)-\cos \left(2 \phi_{1}\right)\right) . \\
& \left\langle u^{\prime} v^{\prime}\right\rangle=\frac{b_{22} \cos \left(\phi_{1}\right) \csc ^{2}\left(\phi_{2}\right)-b_{21} \cos \left(\phi_{2}\right) \csc ^{2}\left(\phi_{1}\right)}{\cos \left(\phi_{1}\right)-\cos \left(\phi_{2}\right)} .
\end{aligned}
$$

Unfortunately, not much information is given regarding any experimental study, and hence, the validity and reliability of this technique remains unknown. Nevertheless, the technique remains a potential solution to measuring turbulence in complex terrain. Using a different scanning strategy, Gal-Chen et al. (1992) was one of the first to employ RHI scanning to estimate $R_{i j}$. They used a pulsed $\mathrm{CO}_{2}$ Doppler lidar in the mean wind direction and perpendicular to the mean wind direction. The equations for $\left\langle v_{\mathrm{r}}^{\prime 2}\right\rangle$ are given as

$\left\langle v_{\mathrm{r}}^{\prime 2}\right\rangle=\left\langle u^{\prime 2}\right\rangle \sin ^{2} \phi+\left\langle w^{\prime 2}\right\rangle \cos ^{2} \phi \pm\left\langle u^{\prime} w^{\prime}\right\rangle \sin (2 \phi)$,

for the lidar beam aligned in the mean wind direction. The \pm sign for $\left\langle u^{\prime} w^{\prime}\right\rangle$ indicates whether the wind is blowing away from or towards the lidar beam. Similarly, for the cross-wind direction we have

$\left\langle v_{\mathrm{r}}^{\prime 2}\right\rangle=\left\langle v^{\prime 2}\right\rangle \sin ^{2} \phi+\left\langle w^{\prime 2}\right\rangle \cos ^{2} \phi \pm\left\langle v^{\prime} w^{\prime}\right\rangle \sin (2 \phi)$,

where the \pm sign indicates positive or negative cross wind beam direction. Equations (32) and (33) are then solved using the least squares analysis to obtain components of $R_{i j}$ (except $\left\langle u^{\prime} v^{\prime}\right\rangle$ ). A method to estimate $\varepsilon$ is also provided using the one-dimensional longitudinal spectrum. In the inertial subrange, the following relation is known (Pope, 2000):

$F_{11}\left(k_{1}\right)=C_{1} \varepsilon^{2 / 3} k_{1}^{-5 / 3}$,

where $F_{11}\left(k_{1}\right)$ is the one-dimensional spectrum of the longitudinal wind field component, and $C_{1} \approx 0.5$ is the Kolmogorov constant related to $F_{11}\left(k_{1}\right)$. The spectrum is measured using a lidar at low elevation angle, and the inertial range can be established by fitting the $-5 / 3$ slope to the spectrum measurements. $\varepsilon$ can then be estimated using Eq. (34), provided that the averaging is taken care of or can be ignored.
An innovative method was also provided to compute the surface heat flux using the third moment of the vertical velocity by the following equation:

$\frac{\partial}{\partial z}\left(\frac{1}{2}\left\langle w^{\prime 3}\right\rangle\right)=\frac{1}{\rho}\left\langle w^{\prime} \frac{\partial p^{\prime}}{\partial z}\right\rangle-\frac{\varepsilon}{3}+\frac{g}{\theta_{T}}\left\langle w^{\prime} \theta_{T}^{\prime}\right\rangle$,

where $\left\langle w^{\prime 3}\right\rangle$ is the third moment of the vertical velocity, $z$ is the height above the ground, $\partial / \partial z$ is the vertical gradient, $p^{\prime}$ is the pressure fluctuation, $\rho$ is the air density at the surface, $\theta_{\mathrm{T}}$ is the surface potential temperature, and $\left\langle w^{\prime} \theta_{\mathrm{T}}^{\prime}\right\rangle$ is the sensible heat flux. Wyngaard and Cote (1971) showed that the pressure covariance term at the surface is negligible, and thus can be neglected in the surface measurements. $\left\langle w^{\prime 3}\right\rangle$ can be measured using lidar measurements, and hence $\left\langle w^{\prime} \theta^{\prime}\right\rangle$ can be measured indirectly using Eq. (35). It should be noted that the averaging time required for the third moments are significantly larger than those required to compute the lower order moments, owing to its influence on the systematic and random errors (Lenschow et al., 1994). Again, owing to the measurement heights of interest, no reference instrument was available, and hence, the reliability of lidar measurements is unknown. It should also be noted that at small elevation angles, the assumption of horizontal homogeneity may not be valid, and one has to take this into account when interpreting the lidar measurements.

In all of the above studies with a Doppler lidar (or radar), the estimated turbulence statistics from the lidar measurements will be subjected to different levels of volume averaging errors, depending on the type of lidar (C-W or pulsed), height above the ground, and the turbulence structure in the atmosphere (Sathe et al., 2011b). None of the aforementioned studies have attempted to correct the turbulence statistics for the errors due to finite probe volume of a lidar, possibly because many were interested to measure in the convective boundary layer. In this layer, the turbulence scales are quite large (Wyngaard, 2010), and perhaps probe volume averaging does not matter. However, if the measurements are desired closer to the ground, particularly in the first $200 \mathrm{~m}$ above the ground where the wind turbines operate, then one must account for the averaging effects in the probe volume. Frehlich (1994) and Frehlich et al. (1994) demonstrated this averaging effect in the measurement of the structure function, where for smaller separation distances the averaging effect was more pronounced. Smalikho (1995) was the first to derive explicit formulae to account for the small-scale filtering effect of the finite probe volume for a $\mathrm{C}-\mathrm{W}$ lidar. The formulae for the estimation of $\varepsilon$ were derived using three different methods for a staring lidar, i.e., using

- the width of the Doppler spectrum,

- the velocity structure function, and

- the one-dimensional velocity spectrum. 
He derived the following expression for the width of the Doppler spectrum:

$\left\langle\sigma_{\mathrm{s}}^{2}\right\rangle=1.22 C \varepsilon^{2 / 3} l^{2 / 3}$,

where $\left\langle\sigma_{\mathrm{s}}^{2}\right\rangle$ is the second central moment of the Doppler spectrum (or its width), and $l$ is the Rayleigh length (which for a $\mathrm{C}-\mathrm{W}$ lidar is the same as the half-width half-maximum of the weighting function of the probe volume). It should be noted that there is a slight difference in the value of the Kolmogorov constant used in Banakh et al. (1999), although the same Eq. (36) is also stated in Smalikho (1995), i.e., in Eq. (25) of Smalikho (1995) the value of Kolmogorov constant is $\approx 1.83$, whereas in Eq. (13) of Banakh et al. (1999), the value of Kolmogorov constant is $\approx 2$. For a continuous wave lidar $\varphi(s)$ is well approximated by a Lorentzian function (Sonnenschein and Horrigan, 1971), and $l=\lambda_{\mathrm{b}} d_{\mathrm{f}}^{2} / \pi r_{\mathrm{b}}^{2}$, where $\lambda_{\mathrm{b}}$ is the wavelength of the emitted radiation, and $r_{\mathrm{b}}$ is the beam radius. $\left\langle\sigma_{\mathrm{s}}^{2}\right\rangle$ can be measured and $l$ is known, so $\varepsilon$ can be estimated. The limitation of this method is that Eq. (36) can only be used when $l \ll \mathcal{L}$, where $\mathcal{L}$ is the outer scale of turbulence. Moreover, the effect of mean radial velocity gradient within the probe volume has not been taken into account. Equation (36) states that if there is no turbulence, then the Doppler spectral width should be zero. However, if there is a mean change of $v_{\mathrm{r}}$ with $s$ (within the probe volume) then there is an additional term proportional to $l^{2}$. If the lidar is C-W and the shear is linear, then the coefficient of $l^{2}$ is infinite (Mann et al., 2010) and we cannot use this method.

The expression for the structure function was derived using the assumption of local isotropy in the inertial subrange. Kristensen et al. (2011) re-derived the expression in great detail, where the probe volume weighting function is assumed be Lorentzian. The expression is given as

$\tilde{D}\left(r_{1}\right)=C \varepsilon^{2 / 3} l^{2 / 3} \frac{\Gamma(1 / 3)}{5 \sqrt{\pi} \Gamma(5 / 6)} \int_{0}^{2 \pi}\left(1-\frac{8}{11} \cos ^{2} \xi\right) \Psi\left(r_{1}, \Theta, \xi\right) \mathrm{d} \xi$,

where $\tilde{D}\left(r_{1}\right)$ is the filtered radial velocity structure function measured by the lidar, $r_{1}=\langle u\rangle t$ is the separation distance along the $x_{1}$ axis, $\Gamma(n)=\int_{0}^{\infty} x^{n-1} \exp (-x) \mathrm{d} x$ is the gamma function, $\Theta$ is the angle between the lidar beam and the mean wind $\langle u\rangle$, and

$$
\begin{aligned}
& \Psi\left(r_{1}, \Theta, \xi\right)=\frac{3}{2} \Gamma\left(\frac{1}{3}\right)\left(\left(\cos ^{2} \xi+\left(\frac{r_{1}}{l}\right)^{2} \cos ^{2}(\xi+\Theta)\right)^{1 / 3}\right. \\
& \left.\cdot \cos \left(\frac{2}{3} \tan ^{-1}\left(\frac{r_{1}}{l}\left|\frac{\cos (\xi+\Theta)}{\cos \xi}\right|\right)\right)-|\cos \xi|^{2 / 3}\right)
\end{aligned}
$$

$r_{1}$ is computed using the Taylor's hypothesis (Taylor, 1938), where turbulence is assumed to be advected by the mean wind $\langle u\rangle$ in time $t$. For the measured and known parameters $\tilde{D}\left(r_{1}\right), r_{1}, l$ and $C$, the unknown $\varepsilon$ can be estimated, where the one-dimensional integral in Eq. (37) can be solved numerically. Using a similar approach, Smalikho (1995) and
Kristensen et al. (2011) also derived the expressions for the one-dimensional velocity spectrum. However, due to the equivalence of the structure function and spectrum approach, the equation is not explicitly stated here.

The limitation of the structure function approach using a staring Doppler lidar is that if there is little or no mean wind then Taylor's hypothesis is violated and the structure functions cannot be estimated. In order to counter these limitations Banakh et al. (1996) proposed a novel technique to estimate $\varepsilon$ using the VAD scanning. Instead of measuring the structure function based on a separation distance $r_{1}$ and using the Taylor's hypothesis, it is measured based on an angular separation distance, $d_{\mathrm{f}} \delta$, on the base of the scanning cone, where $\delta=2 \sin ^{-1}(\sin \phi \sin \theta)$ is the angle subtended by the two lidar beams in a VAD scanning. There is, however, an assumption that the scanning speed is much larger than the advection speed of the turbulence. Kristensen et al. (2012) re-derived the expressions using this approach but disregarded the contribution due to random instrumental noise that was considered in Banakh et al. (1996). For modern lidar systems, the instrumental noise can be neglected (Mann et al., 2009); however, it was found to be significant for older systems (Frehlich et al., 1998; Drobinski et al., 2000), and hence one must be careful before neglecting it. Two approaches were chosen in the derivation by Kristensen et al. (2012): time-domain autocorrelation approach, and the Fourier-domain wave-number approach. The Fourier-domain approach is derived for a C-W lidar (assuming a Lorentzian function), whereas the time domain approach provides expressions as a function of $\varphi(s)$. By using appropriate $\varphi(s)$, the time-domain expressions can be applied for a C-W or a pulsed lidar. The equations using both approaches are as follows. In the time domain,

$$
\begin{aligned}
& \tilde{D}(\delta)=2(1-\cos \delta) R(0) \\
& +\frac{9}{55} \Gamma\left(\frac{1}{3}\right) C\left(\varepsilon d_{\mathrm{f}}\right)^{2 / 3} \int_{-\infty}^{\infty} \int_{-\infty}^{\infty} \varphi\left(s_{1}^{\prime}\right) \varphi\left(s_{2}^{\prime}\right) \\
& \cdot\left(3\left(\left(\left(s_{2}^{\prime}-s_{1}^{\prime}\right)^{2}+4 s_{1}^{\prime} s_{2}^{\prime} \sin ^{2}(\delta / 2)\right)^{1 / 3} \cos \delta-\left|s_{2}^{\prime}-s_{1}^{\prime}\right|^{2 / 3}\right)\right. \\
& \left.+\frac{s_{1}^{\prime} s_{2}^{\prime} \sin ^{2} \delta}{\left(\left(s_{2}^{\prime}-s_{1}^{\prime}\right)^{2}+4 s_{1}^{\prime} s_{2}^{\prime} \sin ^{2}(\delta / 2)\right)^{2 / 3}}\right) d s_{1}^{\prime} d s_{2}^{\prime}
\end{aligned}
$$

where $\tilde{D}(\delta)$ is the filtered radial velocity structure function for a separation distance, $d_{\mathrm{f}} \delta$, on the base of the cone, $R(0)=\left\langle u^{\prime 2}\right\rangle=\left\langle v^{\prime 2}\right\rangle=\left\langle w^{\prime 2}\right\rangle$ for isotropic turbulence, and $s_{1}^{\prime}=s_{1} / d_{\mathrm{f}}, s_{2}^{\prime}=s_{2} / d_{\mathrm{f}}$ are non-dimensional variables. In the Fourier domain, for a C-W lidar, 


$$
\begin{aligned}
& \tilde{D}(\delta)=2(1-\cos \delta) R(0)+C\left(\varepsilon d_{\mathrm{f}}\right)^{2 / 3} \frac{3}{55} \Gamma\left(\frac{1}{3}\right) \\
& \cdot\left(\frac{3}{\sqrt[3]{2}}(1+7 \cos \delta) \sin ^{2 / 3}(\delta / 2)-18\left(\frac{d_{\mathrm{f}}}{l}\right)^{-2 / 3}\right. \\
& +\frac{1}{\pi}\left(\frac{2 d_{\mathrm{f}}}{l}\right)^{-2 / 3} \int_{0}^{\pi / 2} \frac{\Gamma(1 / 2) \Gamma(1 / 3)}{\Gamma(5 / 6)}(7 \cos \delta-4 \cos (2 \xi)) \\
& \cdot\left(2 \cos \left(\frac{2}{3} \tan ^{-1}\left(\frac{4 d_{\mathrm{f}} \sin (\delta / 2) \sin \xi}{l(|\cos (\xi+\delta / 2)|+|\cos (\xi-\delta / 2)|)}\right)\right)\right. \\
& \cdot\left((|\cos (\xi+\delta / 2)|+|\cos (\xi-\delta / 2)|)^{2}+16\left(\frac{d_{\mathrm{f}}}{l}\right)^{2} \sin ^{2}(\delta / 2) \sin ^{2} \xi\right)^{1 / 3} \\
& \left.\left.-\left(4 \frac{d_{\mathrm{f}}}{l} \sin (\delta / 2) \sin \xi\right)^{2 / 3}\right) d \xi\right) .
\end{aligned}
$$

As in the Smalikho (1995) method, the key to using this method is to appropriately select $d_{\mathrm{f}} \delta \ll \mathcal{L}$, so that turbulence is measured in the inertial subrange, and is locally isotropic. $D(\delta)$ can be measured using a lidar; then, by knowing $R(0)$, we can estimate $\varepsilon$. Banakh et al. (1996) did not include the $R(0)$ term in their equation, perhaps because at $\delta \ll \pi / 2$, and $d_{\mathrm{f}} \gg \mathcal{L}$, this term is negligible. The advantage of using Eq. (40) is that we need to solve only a single integral numerically, whereas in Eq. (39) we need to solve a double integral numerically, and that may increase the numerical error. The estimation of $R(0)$ can be quite challenging, since it also contains information about the large-scale turbulence. Kristensen et al. (2012) used empirical models for convective turbulence (Kristensen et al., 1989) and estimated that $R(0)=1.74 \varepsilon^{2 / 3}\left(d_{\mathrm{f}} \cos \phi\right)^{2 / 3}$. Alternatively, one may use the von Kármán (1948) energy spectrum and derive expressions for $R(0)$. The experimental verification of the Kristensen et al. $(2011,2012)$ expressions remains to be seen, but the experimental verification of the Smalikho (1995) and Banakh et al. (1996) expressions will be discussed later in the article.

One of the biggest limitations of a C-W lidar is that $l \propto d_{\mathrm{f}}^{2}$, and hence measuring at greater heights becomes a problem owing to the large probe volume. A pulsed lidar is then ideally suited for this purpose, since the length of its probe volume remains constant at all heights. To this end, Frehlich (1997) was one of the first to derive expressions for the filtered velocity correlation and structure function measured by a pulsed lidar. Numerical simulations were performed to verify the model in which close agreement was observed. The covariances and structure functions of the radial velocities are expressed as a function of lidar parameters and singlepoint statistics. If the range gate length of a pulsed lidar is defined as $L_{\mathrm{p}}=c \tau / 2$, where $c$ is the speed of light, and $\tau$ is the pulse duration, then Frehlich (1997) derived the following equation for the filtered covariance function of the radial velocity:
$\tilde{R}(r)=\left\langle v_{\mathrm{r}}^{\prime 2}\right\rangle \int_{-\infty}^{\infty} f(x, \mu)(1-\Lambda(\chi|y-x|)) \mathrm{d} x$,

where $r$ is the separation distance along the beam, $y=r / L_{\mathrm{p}}$, $\mu=\sqrt{2 \ln (2)} L_{\mathrm{p}} / l, \chi=L_{\mathrm{p}} / \mathcal{L}$,

$\Lambda(x)=(a x)^{2 / 3}\left(1+(a x)^{b}\right)^{-2 / 3 b}$,

is supposedly the normalized structure function of the radial velocity component, and

$$
\begin{aligned}
& f(x, \mu)=\frac{1}{2 \sqrt{\pi} \mu}\left(\exp \left(-\mu^{2}(x+1)^{2}\right)+\exp \left(-\mu^{2}(x-1)^{2}\right)\right) \\
& +\frac{x}{2}(\operatorname{erf}(\mu(x+1))+\operatorname{erf}(\mu(x-1))-2 \operatorname{erf}(\mu x)) \\
& -\frac{1}{\sqrt{\pi} \mu} \exp \left(-\mu^{2} x^{2}\right)+\frac{\operatorname{erf}(\mu(x+1))}{2}-\frac{\operatorname{erf}(\mu(x-1))}{2},
\end{aligned}
$$

where $f(x, \mu)$ is the filter function for a Gaussian transmitted pulse and a rectangular time window. Frehlich (1997) mentions that Eq. (42) is the universal function given by Kaimal et al. (1972) (but we could not verify that), where, for neutral conditions, $a=0.26278$ and $b=1.1948$, and $\operatorname{erf}(x)=2 / \sqrt{\pi} \int_{0}^{x} \exp \left(-t^{2}\right) \mathrm{d} t$ is the error function. In order to use Eq. (41), it is necessary that $r \ll \mathcal{L}$. The filtered radial velocity structure function is given as

$\tilde{D}(r)=2\left\langle v_{\mathrm{r}}^{\prime 2}\right\rangle \int_{-\infty}^{\infty} f(x, \mu)(\Lambda(\chi|y-x|)-\Lambda(\chi|x|)) \mathrm{d} x$.

In both Eqs. (41) and (44) an empirical $\Lambda(x)$ function is used to express $\tilde{R}(r)$ and $\tilde{D}(r)$ in terms of $\left\langle v_{\mathrm{r}}^{\prime 2}\right\rangle$ and $\mathcal{L}$, but in principle we could also use the von Kármán (1948) model. By measuring $\tilde{R}(r)$ or $\tilde{D}(r)$ using a lidar, $\mathcal{L}$ and $\left\langle v_{\mathrm{r}}^{\prime 2}\right\rangle$ can be obtained by the fitting the measurements to Eqs. (41) or (44). Having obtained $\left\langle v_{\mathrm{r}}^{\prime 2}\right\rangle$, any/all of the Eqs. (13)-(33) can be used to estimate $R_{i j}$.

In an independent study, Banakh and Smalikho (1997b) also derived expressions for the estimation of $\varepsilon$ using a staring pulsed lidar. They followed the same structure function approach as in Smalikho (1995). Using numerical simulation, they compared the performance of their model with the numerical results, and concluded that the relative errors in the estimation of $\varepsilon$ are between $15-20 \%$ for a signal-to-noise ratio equal to or greater than unity. Comparison of the model with the measurements will be more challenging, and possibly provide more confidence in the method. As for the C-W lidar, Kristensen et al. (2011) re-derived the expressions in great detail. Like Frehlich (1997), Kristensen et al. (2011) assumed a Gaussian transmitting pulse. If $w_{p}$ is defined as the pulse width, then Kristensen et al. (2011) introduced a length scale $l_{\mathrm{p}}=\sqrt{L_{\mathrm{p}}^{2} / 12+w_{\mathrm{p}}^{2}}$ and used the same same expression 
as Eq. (37) also for the pulsed lidar, except that $l$ in Eq. (37) is replaced by $l_{\mathrm{p}}$ and the $\Psi\left(r_{1}, \Theta, \xi\right)$ function is now given as

$$
\Psi\left(r_{1}, \Theta, \xi\right)=\frac{3}{2} \Gamma\left(\frac{2}{3}\right)|\cos \xi|^{2 / 3}\left({ }_{1} F_{1}\left(-\frac{1}{3} ; \frac{1}{2} ;-\frac{r_{1}^{2} \cos ^{2}(\xi+\Theta)}{4 l_{\mathrm{p}}^{2} \cos ^{2} \xi}\right)-1\right),
$$

where ${ }_{1} F_{1}(a ; b ; x)$ is the Kummer confluent hypergeometric function (Abramowitz and Stegun, 1965). It is to be noted that using Eqs. (37) and (45), for some combinations of $\alpha$ and $r_{1} / l$ (or $\left.r_{1} / l_{\mathrm{p}}\right), \tilde{D}\left(r_{1}\right)$ becomes negative, but Kristensen et al. (2011) also provide the range within which Eqs. (37) and (45) are valid. An advantage of using a pulsed lidar is also that we do not need to apply Taylor's hypothesis in order to compute the separation distance. Thus, instead of using $r_{1}$ in Eq. (45) we can use the separation distance $r$ (provided that $r \ll \mathcal{L}$ ) along the lidar beam, since a pulsed lidar measures at different range gates simultaneously, and hence measure $\tilde{D}(r)$ along the lidar beam axis (Frehlich, 1997).

For a C-W lidar, it is reasonable to assume that the Doppler spectrum obtains its width mainly due to velocity variations (and perhaps also the mean shear) inside the probe length of the lidar. For a pulsed lidar, this assumption is not reasonable, since some lidar parameters like the finite pulse width also contributes to the width of the Doppler spectra. Extracting turbulence information from the width of a Doppler spectra for a pulsed lidar is then much more challenging. Nevertheless, Smalikho et al. (2005) demonstrated that by depicting the Doppler spectral width as a linear summation of contributions from atmospheric turbulence and lidar parameters, we can successfully measure $\varepsilon$. Using numerical simulations, they concluded that the bias in $\varepsilon$ is very sensitive to the selection of the optimal noise threshold level. Interestingly, they compared the estimations of $\varepsilon$ obtained by the spectral width approach and those obtained by the structure function approach (Frehlich, 1997; Banakh and Smalikho, 1997b), and concluded that at low turbulence levels, the structure function approach results in lower random errors of $\varepsilon$, whereas at higher turbulence levels, the random errors in $\varepsilon$ obtained by the spectral width approach are two times smaller than those obtained by the structure function approach. The experiment was carried out using the RHI scanning, but since no reference instruments were available, the reliability of this technique was unknown.

From the above, it can be seen that the major works on processing raw lidar data and obtaining unfiltered turbulence parameters are based on the filtered radial velocity covariances and structure functions. In all these works, the filter function is obtained by assuming either the isotropy of turbulence in the inertial sub-range or the entire range of turbulence scales. It is well-known, however, that turbulence is not isotropic on all scales of interest (Kaimal et al., 1972; Mann, 1994). Hence, $\left\langle v_{\mathrm{r}}^{\prime 2}\right\rangle$ and $\mathcal{L}$ obtained by fitting the modeled structure function to the measurements (Frehlich et al., 1998) is not entirely reliable. A better solution would then be to use the anisotropic turbulence model (Mann, 1994) in modeling the structure function measured by the lidar, and then fitting it to the measurements (Frehlich et al., 2006; Frehlich and Kelley, 2008). Even using an anisotropic turbulence model may not provide reliable estimates of turbulence statistics under all conditions, e.g., the Mann (1994) model is strictly valid only for homogeneous neutral surface layer. Alternatively, it would be best if we do not need to combine turbulence models with measurements, so that we get more reliable statistics from lidar measurements. Mann et al. (2010) provided one such technique to obtain unfiltered radial velocity variance for a C-W lidar without using any turbulence models. They suggested using the mean Doppler spectra given as

$\left\langle S\left(v_{\mathrm{r}}\right)\right\rangle=\frac{f(\eta)+f\left(\eta^{*}\right)}{\sqrt{8 \pi\left\langle v_{\mathrm{r}}^{\prime 2}\right\rangle}}$,

where $\eta=\left(G l+\mathrm{i} v_{\mathrm{r}}\right) / \sqrt{2\left\langle v_{\mathrm{r}}^{\prime 2}\right\rangle}, G$ is the mean radial velocity gradient, ${ }^{*}$ denotes complex conjugation, and $f(\eta)=$ $\exp \left(\eta^{2}\right)(1-\operatorname{erf} \eta)$. Mann et al. (2010) assumed that the probability density function of $v_{\mathrm{r}}$ at a given position $s$ inside the probe volume is Gaussian distributed, and that $\left\langle v_{\mathrm{r}}^{\prime 2}\right\rangle$ is constant inside the probe volume. A systematic study of the influence of these assumptions on the turbulence statistics has however not been carried out. By fitting Eq. (46) to measurements of $\left\langle S\left(v_{\mathrm{r}}\right)\right\rangle,\left\langle v_{\mathrm{r}}^{\prime 2}\right\rangle$ can be estimated.

\subsection{Classification of the previous works according to the estimated turbulence quantity}

From the previous section, it can be clearly understood that processing raw lidar signals to extract turbulence information is an extremely challenging task. Until the mid- and late 1990s, the focus was more on developing new dataprocessing methods to extract turbulence information. New algorithms for efficiently processing the raw lidar data are still being developed, as seen in the recent work by Mann et al. (2010). Nevertheless, many studies have benefited from the continuous developments in the past, where simulation studies and measurement campaigns have been carried out. Because lidar is not yet an established technology to measure atmospheric turbulence, it is important to compare lidar measurements with a reference instrument, as emphasized in the review article by Wilczak et al. (1996). In their review, lidar technology was termed to be a "young adult" in comparison to sodars and radars. With the recent spurt in the measurement campaigns using lidars, we think that it has grown beyond its status of "young adult".

Table 1 groups the studies that have focused on estimation of turbulence quantities using either simulation or lidar measurements. For each turbulence quantity, the total number of studies is also given. It is evident that significant effort has been focused on estimation of $\varepsilon$, followed by $R_{i j}, \ell_{i j},\left\langle v_{\mathrm{r}}^{\prime 2}\right\rangle$, $\tilde{D}(r), \tilde{F}\left(k_{1}\right)$, and $F_{i j}\left(k_{1}\right)$. 
Table 1. Grouping of the past studies according to the estimated turbulence quantity using a lidar.

\begin{tabular}{|c|c|c|c|}
\hline No. & Quantities Estimated & List of references & Total \\
\hline 1 & $\begin{array}{l}\text { Turbulent kinetic energy dissi- } \\
\text { pation rate, } \varepsilon\end{array}$ & $\begin{array}{l}\text { Kunkel et al. (1980); Gal-Chen et al. (1992); Frehlich et al. } \\
\text { (1994); Banakh et al. (1995b, 1996); Frehlich (1997); Banakh } \\
\text { et al. (1997); Banakh and Smalikho (1997a, b); Frehlich et al. } \\
\text { (1998); Banakh et al. (1999); Drobinski et al. (2000); Frehlich } \\
\text { and Cornman (2002); Davies et al. (2004, 2005); Collier et al. } \\
\text { (2005); Banakh and Werner (2005); Smalikho et al. (2005); } \\
\text { Frehlich et al. (2006); Frehlich and Kelley (2008); Davis et al. } \\
\text { (2008); Frehlich et al. (2008); Lothon et al. (2009); Banakh et al. } \\
\text { (2010); O'Connor et al. (2010); Chan (2011); Dors et al. (2011); } \\
\text { Kristensen et al. (2011, 2012) }\end{array}$ & 29 \\
\hline 2 & $\begin{array}{l}\text { Components of the auto- } \\
\text { covariance matrix, } R_{i j}\end{array}$ & $\begin{array}{l}\text { Kunkel et al. (1980); Eberhard et al. (1989); Gal-Chen et al. } \\
\text { (1992); Frehlich et al. (1998); Cohn et al. (1998); Davies et al. } \\
\text { (2003); Drobinski et al. (2004); Davies et al. (2005); Collier } \\
\text { et al. (2005); Banta et al. (2006); Davis et al. (2008); Pichugina } \\
\text { et al. (2008); Wagner et al. (2009); Tucker et al. (2009); Mann } \\
\text { et al. (2010); Sathe et al. (2011b); Lang and McKeogh (2011) }\end{array}$ & 17 \\
\hline 3 & $\begin{array}{l}\text { Integral turbulent length scale } \\
\ell_{i j}, \text { outer scale of turbulence } \mathcal{L}\end{array}$ & $\begin{array}{l}\text { Frehlich (1997); Frehlich et al. (1998); Cohn et al. (1998); Ba- } \\
\text { nakh et al. (1999); Drobinski et al. (2000); Frehlich and Corn- } \\
\text { man (2002); Davies et al. (2004, 2005); Collier et al. (2005); } \\
\text { Banakh and Werner (2005); Smalikho et al. (2005); Lothon } \\
\text { et al. (2006); Frehlich et al. (2006); Frehlich and Kelley (2008); } \\
\text { Frehlich et al. (2008); Lothon et al. (2009) }\end{array}$ & 16 \\
\hline 4 & Radial velocity variance, $\left\langle v_{\mathrm{r}}^{\prime 2}\right\rangle$ & $\begin{array}{l}\text { Eberhard et al. (1989); Gal-Chen et al. (1992); Frehlich (1997); } \\
\text { Mayor et al. (1997); Frehlich et al. (1998); Drobinski et al. } \\
\text { (2000); Davies et al. (2004); Banakh and Werner (2005); } \\
\text { Frehlich et al. (2006); Frehlich and Kelley (2008); Frehlich et al. } \\
\text { (2008); Branlard et al. (2013) }\end{array}$ & 12 \\
\hline 5 & $\begin{array}{l}\text { Filtered radial velocity spec- } \\
\text { trum, } \tilde{F}\left(k_{1}\right)\end{array}$ & $\begin{array}{l}\text { Banakh et al. (1997); Mayor et al. (1997); Frehlich et al. (1998); } \\
\text { Drobinski et al. (1998); Banakh et al. (1999); Drobinski et al. } \\
\text { (2000); Davies et al. (2004); Mann et al. (2009); Sjöholm et al. } \\
\text { (2009); Kristensen et al. (2011); Dors et al. (2011); Angelou } \\
\text { et al. (2012) }\end{array}$ & 12 \\
\hline 6 & $\begin{array}{l}\text { Filtered radial velocity struc- } \\
\text { ture function, } \tilde{D}(r)\left(\text { or } \tilde{D}\left(r_{1}\right)\right)\end{array}$ & $\begin{array}{l}\text { Frehlich et al. (1994); Frehlich (1997); Banakh and Smalikho } \\
\text { (1997b); Frehlich et al. (1998); Banakh et al. (1999); Frehlich } \\
\text { and Cornman (2002); Davies et al. (2004); Frehlich et al. } \\
\text { (2008); Banakh et al. (2010); Chan (2011); Kristensen et al. } \\
(2011,2012)\end{array}$ & 12 \\
\hline 7 & $\begin{array}{l}\text { One-dimensional spectrum of } \\
\text { the components of the wind } \\
\text { field, } F_{i j}\left(k_{1}\right)\end{array}$ & $\begin{array}{l}\text { Lawrence et al. (1972); Hardesty et al. (1982); Drobinski et al. } \\
\text { (2004); Davies et al. (2005); Lothon et al. (2009); O’Connor } \\
\text { et al. (2010); Canadillas et al. (2010); Sathe and Mann (2012) }\end{array}$ & 8 \\
\hline 8 & Third order moments $\left\langle w^{\prime 3}\right\rangle$ & $\begin{array}{l}\text { Gal-Chen et al. (1992); Cohn et al. (1998); Lenschow et al. } \\
\text { (2000) }\end{array}$ & 3 \\
\hline 9 & Kinematic heat flux, $\left\langle w^{\prime} \theta^{\prime}\right\rangle$ & Gal-Chen et al. (1992); Davis et al. (2008) & 2 \\
\hline 10 & $\begin{array}{l}\text { Coherence of the components } \\
\text { of the wind field, } \operatorname{coh}_{i j}\left(k_{1}\right)\end{array}$ & Lothon et al. (2006); Kristensen et al. (2010) & 2 \\
\hline
\end{tabular}




\subsection{1 $\varepsilon, \tilde{F}\left(k_{1}\right), \tilde{D}(r)$}

The greatest advantage of estimation of $\varepsilon$ is that we can exploit the universal behavior of isotropy in the inertial subrange, either in the Fourier domain (using velocity spectrum) or the temporal domain (using structure function) (Pope, 2000). Thus, estimation of $\varepsilon$ involves estimation of either $\tilde{F}\left(k_{1}\right)$ or $\tilde{D}(r)$ (we could also use the separation distance $r_{1}$ instead of $r$ ) in the inertial subrange from the lidar beam that is oriented in any direction. The associated challenges are then threefold: proving the existence of the inertial subrange, identifying the inertial subrange from the lidar data, and averaging within the probe volume. From Pope (2000), we understand that in order to have a well-defined inertial subrange, we need large Reynolds number flows. Fortunately, atmospheric flows are usually characterized by large Reynolds numbers (Wyngaard, 2010), especially during convective daytime conditions. Stable atmospheric conditions that normally occur during the late night and early morning, can however present challenges since they are associated with low Reynolds number turbulence (Wyngaard, 2010). We can then assume that inertial subrange is well defined for most of the day, except during late night and early morning conditions.

The challenge associated with identifying the inertial subrange from lidar measurements is mainly due to the probe length of a lidar. In principle, we need only one measurement - of either $\tilde{F}\left(k_{1}\right)$ or $\tilde{D}(r)$ - in the inertial subrange. However, in order to avoid statistical uncertainty, it is recommended that one take multiple measurements, and use them all to fit a model. From Mann et al. (2009), Sjöholm et al. (2009) and Sathe (2012), it is clear that due to the probe length of a lidar, most of the turbulence scales in the inertial range are filtered out. Modeling the lidar filter function then becomes inevitable, which has fortunately been carried out by Smalikho (1995), Banakh et al. (1996), Frehlich (1997), Smalikho et al. (2005), Sjöholm et al. (2009) and Mann et al. (2009). In Sjöholm et al. (2009) and Mann et al. (2009), the goal was only to compare the lidar volume-averaged measurements of the radial velocity spectrum with reference point measurements; an estimation of $\varepsilon$ was not carried out. These studies could be extended further to estimate $\varepsilon$ by using the isotropic or anisotropic form of spectral tensor with a given energy spectrum. Apart from the filtering effect, we also need to identify the cut-off low wavenumber range when using $\tilde{F}\left(k_{1}\right)$, and the maximum separation distance when using $\tilde{D}(r)$ in order to identify the inertial subrange.

In summary, there are four ways of estimating $\varepsilon$ : width of the Doppler spectra (Smalikho, 1995; Banakh et al., 1995a, 2010; Smalikho et al., 2005), radial velocity spectrum (Gal-Chen et al., 1992; Banakh et al., 1995b, 1997; Banakh and Smalikho, 1997a; Drobinski et al., 2000; Davies et al., 2005; Davis et al., 2008; Collier et al., 2005; Lothon et al., 2009; O'Connor et al., 2010; Dors et al., 2011; Kristensen et al., 2011), line-of-sight radial velocity structure function
(Frehlich et al., 1994; Frehlich, 1997; Banakh and Smalikho, 1997a, b; Frehlich et al., 1998; Banakh et al., 1999; Frehlich and Cornman, 2002; Davies et al., 2004; Banakh and Werner, 2005; Smalikho et al., 2005), and radial velocity azimuthal structure function (Banakh et al., 1996, 1999; Banakh and Smalikho, 1997a; Frehlich et al., 2006, 2008; Frehlich and Kelley, 2008; Chan, 2011; Kristensen et al., 2012). Very few studies have exploited the Doppler spectral width to estimate $\varepsilon$; the reasons could be that for a C-W lidar the applicability of the Doppler spectral width is limited to $l \ll \mathcal{L}$, and for a pulsed lidar it is quite complicated to process the data (Smalikho et al., 2005). Nevertheless, as shown by Banakh et al. (2010), for a pulsed lidar it could be advantageous to use the Doppler spectral width approach, since the random errors in $\varepsilon$ can be reduced at higher turbulence levels than they can in the structure function approach, or equally, using the radial-velocity-spectrum approach.

\subsection{2 $\left\langle v_{\mathrm{r}}^{\prime 2}\right\rangle, \ell_{i j}, \mathcal{L}$}

Apart from $\varepsilon$, another important parameter that characterizes turbulence is the length scale. The two most commonly used definitions of the length scale are $\ell_{i j}$ and $\mathcal{L}$, which have physically different interpretations. $\mathcal{L}$ (also called the outer length scale of turbulence) is the length scale corresponding to the maximum spectral energy, whereas $\ell_{i j}$ can be interpreted as the length scale up to which turbulence is correlated. The two scale lengths can, however, be shown to be related to each other, as was done by Frehlich and Cornman (2002), Smalikho et al. (2005) and Lothon et al. (2006). Thus, $\ell_{i j}$ can be estimated from its relationship with $\mathcal{L}$ (Frehlich and Cornman, 2002; Davies et al., 2004; Collier et al., 2005; Smalikho et al., 2005; Lothon et al., 2006, 2009; Frehlich et al., 2006), or by using the definition given in Eq. (3) (Cohn et al., 1998). Practically, $\ell_{i j}$ is estimated from the values of the autocorrelation function at the first zero crossing, but Davies et al. (2005) estimated the same using some properties of the autocorrelation function. $\mathcal{L}$ can be estimated using the structure function approach (Frehlich, 1997; Frehlich et al., 1998, 2008; Frehlich and Kelley, 2008). Drobinski et al. (2000) followed a slightly different approach, in which the radial velocity spectrum is split into two regions; one is the energycontaining range, and the other contains the inertial subrange up to the dissipation range. Measurements of the radial velocity spectrum can thus be fitted to this model and $\mathcal{L}, \varepsilon$ estimated simultaneously. Interestingly, Banakh et al. (1999) and Banakh and Werner (2005) also use the term outer length scale for $\ell_{i j}$, but we believe that it is important to distinguish between the two length scales.

Fewer studies have been carried out to estimate $\left\langle v_{\mathrm{r}}^{\prime 2}\right\rangle$ than to estimate to $\varepsilon$ (see Table 1 ). This is perhaps because information of all turbulence scales is required to estimate $\left\langle v_{\mathrm{r}}^{\prime 2}\right\rangle$, and a universal isotropic relation does not suffice. Although Eberhard et al. (1989) and Gal-Chen et al. (1992) have estimated $\left\langle v_{\mathrm{r}}^{\prime 2}\right\rangle$ from lidar measurements, no consideration to 
probe volume averaging was given, and thus any other turbulence statistic derived using these measurements would not contain information on small-scale turbulence. All subsequent studies have followed the pioneering work of Frehlich (1997), in which information about small-scale turbulence was recovered by modeling the filter function. The main contributions of the Frehlich (1997) method are first, that it presents a technique to derive expressions of the radial velocity structure function (or, equivalently, the radial velocity spectrum) for a lidar pulse with any given shape; second, it presents a turbulence model, with which we can estimate $\left\langle v_{\mathrm{r}}^{\prime 2}\right\rangle$ and $\ell_{i j}$. One can thus use a non-Gaussian shape for the pulse and derive a different functional form of the spatial filter (Davies et al., 2004), or use a different turbulence model, e.g. von Kármán (1948) isotropic spectral tensor model (Frehlich and Cornman, 2002), or a more realistic anisotropic Mann (1994) spectral tensor instead of the empirical Kaimal et al. (1972) models (Frehlich, 1997; Frehlich et al., 1998). Using $\tilde{D}(r)$ to estimate $\left\langle v_{\mathrm{r}}^{\prime 2}\right\rangle$ from a pulsed lidar has the limitation of coarse vertical resolution. An azimuthal structure function approach can then be used to improve the vertical resolution (Banakh et al., 1996; Frehlich et al., 2006; Frehlich and Kelley, 2008; Kristensen et al., 2012). Without using any turbulence model, Mann et al. (2010) suggested a technique (only for C-W lidars) to estimate $\left\langle v_{\mathrm{r}}^{\prime 2}\right\rangle$ using the mean Doppler spectrum. The validity of this technique is successfully demonstrated in Branlard et al. (2013).

\subsection{3 $R_{i j}, F_{i j}\left(k_{1}\right)$}

$R_{i j}$ is one of the most important turbulence statistics used in the wind energy industry, due to the use of $\left\langle u^{\prime 2}\right\rangle$ in the definition of turbulence intensity (IEC, 2005b). Unfortunately, it is also one of the most challenging statistics to obtain from the lidar data, partly due to challenges in data processing, and partly due to economic reasons. If economics is not a major constraint, then three lidars with beams intersecting at one point will provide spatially filtered turbulence statistics (Mann et al., 2009). With two lidars, we are restricted to estimating the turbulence statistics of only two components, i.e., horizontal and vertical (Davies et al., 2005; Collier et al., 2005).

Normally, the economics of a project are important and we are then restricted to using only one lidar. In this case, a lidar beam can be oriented in the direction of the turbulence statistic that we are interested in estimating. For example, if we are interested in estimating $\left\langle u^{\prime 2}\right\rangle$, then ideally the lidar beam should be pointed horizontally in the mean wind direction at the height of interest, and for the period within which $\left\langle u^{\prime 2}\right\rangle$ is obtained (Lawrence et al., 1972). For a ground-based lidar system this would be impossible since the beam would only measure wind that is very close to the ground. Alternatively, we could point the lidar beam at a very small elevation angle and assume that the contributions from the vertical velocity are negligible (Drobinski et al., 2004; Collier et al., 2005; Banta et al., 2006; Pichugina et al., 2008). An open question then is, how small the elevation should be so that the vertical velocity contributions can be neglected? Drobinski et al. (2004), Banta et al. (2006), and Pichugina et al. (2008) neglected the vertical velocity contributions up to an elevation angle of $20^{\circ}$, but provided no justification for the assumption of negligible vertical velocity contributions. This method also requires that the horizontal homogeneity assumption is valid over a larger area, particularly if we are interested in measuring turbulence statistics at greater heights and/or several heights. Measurements of $\left\langle w^{\prime 2}\right\rangle$ can be relatively easier to take, since we only need to point the beam in the vertical direction (Cohn et al., 1998; Tucker et al., 2009). In principle, following Frehlich (1997) and Banakh and Smalikho (1997b) approach, we can then obtain unfiltered $\left\langle w^{\prime 2}\right\rangle$ from $\left\langle v_{\mathrm{r}}^{\prime 2}\right\rangle$.

$R_{i j}$ can also be obtained using scanning lidar data, either using RHI scanning (Gal-Chen et al., 1992; Davies et al., 2003; Davis et al., 2008) or VAD scanning (Eberhard et al., 1989; Mann et al., 2010). If, say for a VAD scanning, we use high-frequency $v_{r}$ measurements, deduce the $u, v$, and $w$ components at every measurement time step, and obtain, say, $\left\langle u^{\prime 2}\right\rangle$ or $F_{11}\left(k_{1}\right)$, then apart from the probe volume averaging effect, large systematic errors will also be introduced in the measurement of $\left\langle u^{\prime 2}\right\rangle$ due to the contamination by the diagonal and cross components of $\mathbf{R}$ (Sathe et al., 2011b; Sathe and Mann, 2012). In such cases, one should be very careful in using the $R_{i j}$ measurements obtained from a scanning lidar, since removing only the probe volume filtering effect (Wagner et al., 2009) without giving consideration to cross-contamination, or neglecting the effects of systematic errors completely (Lang and McKeogh, 2011) will provide erroneous values. Using $\left\langle v_{\mathrm{r}}^{\prime 2}\right\rangle$ instead of high frequency $v_{\mathrm{r}}$ measurements to obtain $R_{i j}$ is then essential in order to avoid contamination by the components of $\mathbf{R}$ (Eberhard et al., 1989; Gal-Chen et al., 1992; Mann et al., 2010; Sathe, 2012). The unfiltered $\left\langle v_{\mathrm{r}}^{\prime 2}\right\rangle$ can be obtained using methods suggested by Frehlich (1997) and Mann et al. (2010), and hence unfiltered $R_{i j}$ can also be obtained.

Estimating $F_{i j}\left(k_{1}\right)$ from lidar data is even more challenging than estimating $R_{i j}$, since we need high frequency measurements of $v_{\mathrm{r}}$. For a scanning lidar (e.g., VAD), combining high frequency measurements from the lidar beams oriented in different directions results in erroneous measurements of $F_{i j}\left(k_{1}\right)$ (Canadillas et al., 2010; Sathe and Mann, 2012). Most studies in the past have thus used either a staring lidar configuration (Lawrence et al., 1972; Davies et al., 2005; Lothon et al., 2009; O'Connor et al., 2010), or neglected contributions from the $w$ component at small elevation angles (Hardesty et al., 1982; Drobinski et al., 2004). 


\subsection{4 $\left\langle w^{\prime 3}\right\rangle,\left\langle w^{\prime} \theta^{\prime}\right\rangle, \operatorname{coh}_{i j}\left(k_{1}\right)$}

Very little effort has been focused on the estimation of $\left\langle w^{\prime 3}\right\rangle$, $\left\langle w^{\prime} \theta^{\prime}\right\rangle$ and $\operatorname{coh}_{i j}\left(k_{1}\right)$. One of the reasons could be the complexity of data processing and the associated errors that present great challenges to their estimations. Particularly, an estimation of $\left\langle w^{\prime} \theta^{\prime}\right\rangle$, requires not only an estimation of $\varepsilon$, but also requires estimation of either $\left\langle w^{\prime 3}\right\rangle$ (Gal-Chen et al., 1992), or $\left\langle w^{\prime 2}\right\rangle$ (Davis et al., 2008). Estimating higher order moments, particularly third and fourth order, introduce large errors in the measurements (Lenschow et al., 1994, 2000). Fortunately, we can reduce the errors in higher moments using the autocorrelation technique (Lenschow et al., 2000) or the spectral technique (Frehlich et al., 1998), which increase the potential of estimating the heat flux using Eq. (35).

\section{Turbulence quantities of interest for future applications in wind energy}

Wind turbines have been and will be installed in different parts of the world where atmospheric conditions differ significantly from each other. The reason why turbulence is important for wind energy purposes is already given in Sect. 1. Here we will specifically discuss those parameters listed in Table 1 that are useful for wind energy. According to IEC (2005a) standards, a wind turbine should be designed for different classes of turbulence intensities. The turbulence intensity $I$ is defined as the ratio of standard deviation of the $u$ component to the mean horizontal wind speed $\left(I=\sqrt{\left\langle u^{\prime 2}\right\rangle} /\langle u\rangle\right)$. It is thus crucial to perform measurements of $\left\langle u^{\prime 2}\right\rangle$. Apart from $I$, it also important to measure the mean wind speed profile, which is dependent on the velocity covariances $\left\langle u^{\prime} w^{\prime}\right\rangle$ and $\left\langle v^{\prime} w^{\prime}\right\rangle$ (Wyngaard, 2010). The diagonal components of $\mathbf{R}$, i.e., $\left\langle u^{\prime 2}\right\rangle,\left\langle v^{\prime 2}\right\rangle$ and $\left\langle w^{\prime 2}\right\rangle$ influence the wind turbine loads significantly. Thus for wind energy purposes, it is very important to measure $R_{i j}$; however, to do this using lidars, we see from Eq. (12) that we need measurements of $\left\langle v_{\mathrm{r}}^{\prime 2}\right\rangle$. In order to get unfiltered $\left\langle v_{\mathrm{r}}^{\prime 2}\right\rangle$ measurements (as seen in Sect. 4) with the state-of-the-art methods, we need to fit lidar measurements of $\tilde{D}(r)$ and/or $\tilde{F}\left(k_{1}\right)$ to some isotropic or anisotropic turbulence models.

A current practice in the wind energy industry to perform load simulations is that a turbulent wind field is generated using either the Mann (1994) model or an empirical Kaimal et al. (1972) spectrum is combined with some coherence model (IEC, 2005a). As discussed in Sect. 2, the need to measure $\varepsilon$ and $\mathcal{L}$ is then clearly evident. These parameters are normally obtained by fitting the Mann (1994) model to the measurements of $F_{i j}\left(k_{1}\right)$, which could be obtained using lidars. $\mathcal{L}$ and $\operatorname{coh}_{i j}\left(k_{1}\right)$ are important for estimating the loads and wake meandering (Larsen et al., 2008). The influence of atmospheric stability on wind speed profile and on wind turbine loads is becoming increasingly evident (Sathe

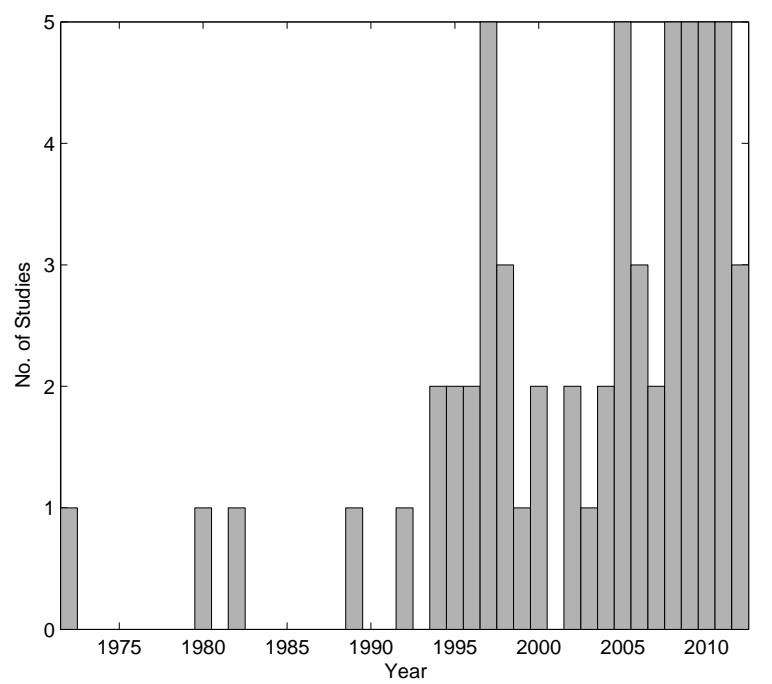

Fig. 4. Number of studies per year on lidar turbulence measurements.

et al., 2011a, 2012). For this reason, measurement of $\left\langle w^{\prime} \theta^{\prime}\right\rangle$ is quite important for wind energy. According to Lenschow et al. (1994), $\ell_{i j}$ is useful in estimating the averaging time required to keep the random errors below a certain threshold for a particular turbulence statistic, and hence is a desirable measurement quantity for wind energy purposes.

Recently, lidars are being contemplated to be used for wind turbine control. The concept is such that the lidar is either placed on a nacelle of a wind turbine (Schlipf et al., 2012), or mounted inside a spinner (Mikkelsen et al., 2012; Simley et al., 2013) in order to detect the incoming wind field and carry out a feed-forward control to reduce the structural loads on a wind turbine. The degree to which such a concept can be successfully applied depends on how well the lidars are able to detect the incoming turbulent structures. From Sathe et al. (2012) we understand that different components of a wind turbine are affected by different scales of turbulent structures. It is thus important to be able to detect the range of turbulence scales, up to the order of or less than the probe volume length.

\section{Summary and discussion}

Figure 4 summarizes the number of studies that have significantly contributed to the research on turbulence measurements using wind lidars from 1972-2012. Research on lidar turbulence measurements dates back to 1972, but it was not until 1997 that the publication rate picked up pace. If we consider that the lidar turbulence measurement research encompasses the period 1972-2012, then more than $80 \%$ of the research was carried out in the latter half of the $30 \mathrm{yr}$ period, i.e., from 1997-2012. In the first $15 \mathrm{yr}$ of development, barring the works of Smalikho (1995) and Banakh 
et al. (1996), focus was more on extracting turbulence information without taking into account probe volume averaging (see Sect. 4). Since then substantial effort has been put into modeling the averaging effect inside the lidar probe volume, mainly by Professor V. A. Banakh and Dr. I. N. Smalikho from the V. E. Zuev Institute of Atmospheric Optics of Russian Academy of Sciences, Siberian Branch, Russia, and the late Dr. R. Frehlich from the University of Colorado, USA. Interestingly, these scientists pioneered new processing algorithms independently of each other during roughly the same period, i.e. from the mid 1990s until the mid 2000s, wherein they demonstrated how to extract unfiltered turbulence parameters (Smalikho, 1995; Banakh et al., 1996; Frehlich, 1997; Banakh and Smalikho, 1997b; Smalikho et al., 2005; Frehlich et al., 2006). We believe that this development has significantly contributed to the number of research studies carried out in the last $15 \mathrm{yr}$. Further development in processing algorithms will also greatly benefit from their works. We expect that the number of such studies will continue to increase due to increase in wind-energy development all over the world.

That brings us to an obvious question: is there anything new to be discovered with regards to processing raw lidar data, scanning configurations, or the technology itself that can provide more reliable turbulence measurements using lidars? We attempt to answer this question as follows:

1. Raw lidar data processing - up until now, the processing algorithms that have been developed have shown that by combining an isotropic turbulence model with lidar measurements, we are able to estimate $\varepsilon,\left\langle v_{\mathrm{r}}^{\prime 2}\right\rangle$ and $\mathcal{L}$ (see Table 1). However, turbulence is not isotropic in all range of scales. Anisotropy is particularly observed on longer length scales, and thus it is more desirable to estimate $\left\langle v_{\mathrm{r}}^{\prime 2}\right\rangle$ and $\mathcal{L}$ by combining an anisotropic turbulence model (Kristensen et al., 1989; Mann, 1994) with the lidar measurements. This recommendation was also made by Frehlich et al. (2006) and Frehlich and Kelley (2008). There is, however, a need for developing algorithms that make as little use of models as possible in combination with the measurements. Even an anisotropic turbulence model such as that developed by Mann (1994) is based on a set of assumptions, e.g. neutral atmospheric conditions, applicability in the surface layer, validity of Taylor's hypothesis, and it does not apply to complex terrain. If we then combine such a model with lidar measurements, and estimate turbulence parameters, then additional uncertainties may be introduced. In order to avoid such situations, further development of algorithms should also focus on making use of only raw lidar data to extract turbulence parameters, e.g., as shown in Mann et al. (2010).

Furthermore, from the study by Sathe et al. (2011b) and Sathe and Mann (2012), it is now clear that in

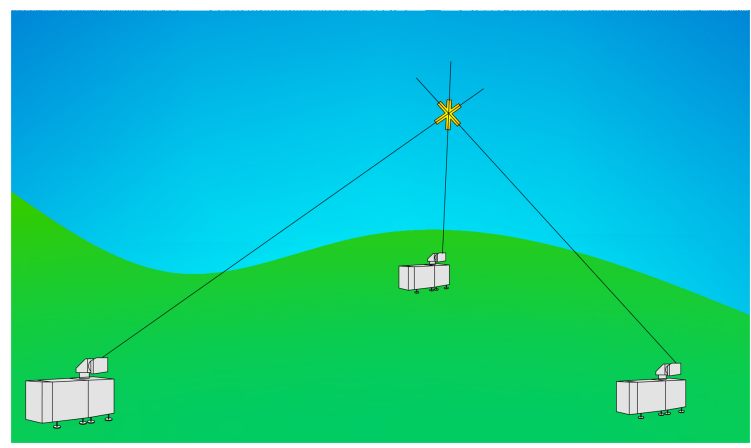

Fig. 5. Three lidars intersecting at a point.

a VAD scanning configuration, obtaining $u, v$ and $w$ components from $v_{\mathrm{r}}$ data at each time step and then deducing turbulence statistics will introduce large systematic errors in the turbulence measurements. One might argue that under some conditions the lidar-tosonic correlation may be close to 1 , but, as shown in Sathe et al. (2011b), the correlation would depend on the type of lidar ( $\mathrm{C}-\mathrm{W}$ or pulsed), and the turbulence structure. The correlations with any reference instrument may not be repeatable if the experiment is conducted during different times of the day. It is thus recommended that such a data-processing method should not be followed. Alternatively, as shown by Wilson (1970), Kropfli (1986), Eberhard et al. (1989) and Mann et al. (2010), using $\left\langle v_{\mathrm{r}}^{\prime 2}\right\rangle$ instead of $v_{\mathrm{r}}$ to deduce $R_{i j}$ is a fundamentally correct method to extract turbulence information from the raw lidar data.

2. Scanning configurations - three measurement configurations have been used until now: staring, VAD, and RHI scanning (see Sect. 3 for details of the scanning configurations). Ideally, using three staring lidars with their beams crossing at a point (similar to sonic anemometer beams) would provide more reliable measurements as compared to using a single lidar in a VAD or RHI scanning mode. Figure 5 illustrates this concept. The necessity of making assumptions of horizontal homogeneity is reduced significantly, and potentially it can provide measurements in complex terrain with increased reliability. The only challenge then is to tackle the probe volume averaging effect in the individual beam direction. A step in this direction is the use of two lidars (Davies et al., 2004, 2005; Collier et al., 2005). In VAD or RHI scanning, the assumption of horizontal homogeneity is inevitable, and thus restricts the applicability of VAD and RHI scanning for wind energy purposes, particularly in complex terrain. Bingöl et al. (2009) provided a technique to correct for terrain-induced inhomogeneities in the mean flow. For turbulence measurements we can use Taylor series expansion in the horizontal plane as shown by 
Frisch (1991). The reliability of this algorithm has not been investigated thoroughly, but could form the basis of a potential study for the future.

On the other hand, using three lidars can increase the cost of a project significantly, a fact which hinders the use of this method in wind energy development. If we use a single staring lidar at one height, then it becomes almost unavoidable to combine a turbulence model with lidar measurements in order to extract turbulence information (Smalikho, 1995). Another aspect to be considered when deciding on the scanning configuration is the sampling frequency. In this regard, the staring configuration will again provide faster measurements than the scanning configurations. In a VAD scanning, there is scope for reducing the number of measurement points on a scanning circle. As shown by Eq. (12) we need only six beams at different azimuth and half-opening angles to estimate $R_{i j}$. However, using random six points will introduce random errors in the turbulence measurements. Sathe (2012) provided some initial calculations of the optimum configuration to minimize random errors. The sampling frequency would thus be increased, but further investigations are required before this configuration can be put into use.

3. Improvement in lidar technology - new, cheaper solidstate lasers for coherent detection lidars with integrated optical amplification are being developed and tested (Hansen and Pedersen, 2008; Rodrigo and Pedersen, 2008). These may greatly expand the use of lidars for wind measurements, but they are not specifically tailored for turbulence measurements. Preliminary tests of these lidars have been carried out by Rodrigo and Pedersen (2012), and show good comparison with a sonic anemometer. The solid-state lasers with integrated amplification may in the near future compete with the more expensive lasers used in CW Doppler lidars. Direct detection is still on an experimental level (McKay, 1998) and has only been used in the atmosphere sporadically (Xia et al., 2007; Dors et al., 2011). The simple design of these instruments may eventually lead to cheaper lidar systems. Non-coherent detection may also provide possible new ways to estimate atmospheric turbulence (Mayor et al., 2012; Sela and Tsadka, 2011), but to our knowledge it does not, so far, challenge the capabilities of the coherent Doppler lidars.

Completely new principles could also drastically improve the turbulence-measuring capabilities of lidars. One suggestion is to exploit the translation of the speckle pattern in the image plane of the lidar telescope. In this way, not only the line-of-sight velocity could be estimated, but also the two transverse velocity components. All components would be measured in the same volume, reducing the problem of crosscontamination. In the laboratory, this method has been successfully tested on translating hard targets (Iversen et al., 2011; Jakobsen et al., 2011), but it is much harder to get the method to work with backscatter from atmospheric aerosols. Firstly, the return from the aerosols is much weaker and, secondly, the turbulence may reduce the correlation time of the speckle pattern, which could adversely affect the transverse velocity determination.

In order to meet the objectives stated above, a simulation study can significantly help in better planning and designing the experiments (Frehlich and Cornman, 2002; Banakh and Werner, 2005). A possibly important aspect of turbulence measurements using lidars that we have not considered in this review is the instrumental error, which is generally assumed to be uncorrelated (Frehlich et al., 1998; Lenschow et al., 2000). Fortunately for modern commercial lidar systems, the magnitude of the instrumental error is not significant, and can be safely neglected (Mann et al., 2009). However, for those lidar instruments that have significant instrumental error and therefore could potentially bias turbulence measurements, the techniques suggested by Frehlich et al. (1998), Drobinski et al. (2000) and Lenschow et al. (2000) can be used to perform corrections.

Table A1. Nomenclature.

\begin{tabular}{ll}
\hline$C \approx 1.5$ & universal Kolmogorov constant \\
$C_{1} \approx 0.5$ & Kolmogorov constant related to $F_{11}\left(k_{1}\right)$ \\
$D_{i j}(\boldsymbol{r})$ & velocity structure function \\
$F_{i j}\left(k_{1}\right)$ & one-dimensional velocity spectrum \\
$I$ & longitudinal turbulence intensity \\
$I_{n}$ & Wilson $(1970)$ integrals $(n=1, ., 4)$ to esti- \\
& mate the covariances \\
$L_{\mathrm{p}}$ & range gate length $(c \tau / 2)$ \\
$R_{i j}(\boldsymbol{r})$ & cross covariance function \\
$\mathbf{R}=\mathbf{R}(0)$ & covariance matrix \\
$\boldsymbol{k}$ & wave vector in the Fourier domain \\
$\boldsymbol{n}$ & unit directional vector \\
$\boldsymbol{r}$ & separation vector in three dimensions \\
$\boldsymbol{x}$ & position vector in three dimensions \\
$\operatorname{coh}_{i j}\left(k_{1}\right)$ & coherence function \\
$\left\langle S\left(v_{\mathrm{r}}\right)\right\rangle$ & mean Doppler spectra \\
$\langle u\rangle$ & mean wind speed \\
$\left\langle w^{\prime} \theta^{\prime}\right\rangle$ & sensible heat flux \\
$\left\langle u^{\prime 2}\right\rangle$ & variance of the $u$ component \\
$\left\langle u^{\prime} v^{\prime}\right\rangle$ & covariance between the $u$ and $v$ components \\
$\left\langle u^{\prime} w^{\prime}\right\rangle$ & covariance between the $u$ and $w$ components \\
$\left\langle v_{\mathrm{r}}^{\prime 2}\right\rangle$ & radial velocity variance \\
$\left\langle v^{\prime 2}\right\rangle$ & variance of the $v$ component \\
$\left\langle v^{\prime} w^{\prime}\right\rangle$ & covariance between the $v$ and $w$ components \\
$\left\langle w^{\prime 2}\right\rangle$ & variance of the $w$ component \\
$\left\langle w^{\prime 3}\right\rangle$ & third moment of the vertical velocity \\
&
\end{tabular}


Table A1. Nomenclature.

\begin{tabular}{|c|c|}
\hline $\mathbf{v}$ & wind field vector \\
\hline$\tilde{D}(\delta)$ & $\begin{array}{l}\text { filtered radial velocity structure function for } \\
\text { a separation distance } d_{f} \delta\end{array}$ \\
\hline$\tilde{D}(r)$ & $\begin{array}{l}\text { filtered radial velocity structure function for } \\
\text { a separation distance } r\end{array}$ \\
\hline$\tilde{D}\left(r_{1}\right)$ & $\begin{array}{l}\text { filtered radial velocity structure function for } \\
\text { a separation distance } r_{1}\end{array}$ \\
\hline$\tilde{F}\left(k_{1}\right)$ & filtered radial velocity spectrum \\
\hline$\tilde{R}(r)$ & $\begin{array}{l}\text { filtered covariance function of the radial ve- } \\
\text { locity for a separation distance } r\end{array}$ \\
\hline$a_{n}, b_{n}, a_{m n}, b_{m n}$ & Fourier coefficients \\
\hline$c$ & speed of light \\
\hline$d_{\mathrm{f}}$ & $\begin{array}{l}\text { focus distance for a } \mathrm{C}-\mathrm{W} \text { lidar and center of } \\
\text { the range gate for a pulsed lidar }\end{array}$ \\
\hline$i, j$ & $\begin{array}{l}\text { indices that take values } 1, ., 3 \text { and denote the } \\
\text { component of the wind field }\end{array}$ \\
\hline$k_{1}, k_{2}, k_{3}$ & $\begin{array}{l}\text { components of the wave vector along the } \\
x_{1}, x_{2}, x_{3} \text { axes respectively }\end{array}$ \\
\hline$l$ & Rayleigh length \\
\hline$r$ & separation distance along the lidar beam \\
\hline$r_{1}, r_{2}, r_{3}$ & $\begin{array}{l}\text { separation distances along the } x_{1}, x_{2}, x_{3} \text { axes } \\
\text { respectively }\end{array}$ \\
\hline$r_{\mathrm{b}}$ & lidar beam radius \\
\hline$u$ & $\begin{array}{l}\text { longitudinal component of the wind field in } \\
\text { the } x_{1} \text { direction }\end{array}$ \\
\hline$v$ & $\begin{array}{l}\text { transversal component of the wind field in } \\
\text { the } x_{2} \text { direction }\end{array}$ \\
\hline$v_{\mathrm{r}}$ & radial velocity \\
\hline$w$ & $\begin{array}{l}\text { vertical component of the wind field in the } \\
x_{3} \text { direction }\end{array}$ \\
\hline$w_{\mathrm{p}}$ & pulse width \\
\hline$x_{1}, x_{2}, x_{3}$ & $\begin{array}{l}\text { axes defining the right handed cartesian co- } \\
\text { ordinate system }\end{array}$ \\
\hline$z$ & height above the ground \\
\hline $\mathcal{L}$ & outer length scale of turbulence \\
\hline$\Phi_{i j}(\boldsymbol{k})$ & three-dimensional spectral velocity tensor \\
\hline$\Theta$ & $\begin{array}{l}\text { angle between the lidar beam and the mean } \\
\text { wind }\end{array}$ \\
\hline$\alpha$ & elevation angle \\
\hline$\chi_{i j}\left(k_{1}, r_{2}, r_{3}\right)$ & $\begin{array}{l}\text { cross spectra at separation distances } r_{2} \text { and } \\
r_{3}\end{array}$ \\
\hline$\delta$ & $\begin{array}{l}\text { angle subtended by two lidar beams in a } \\
\text { VAD scanning mode }\end{array}$ \\
\hline$\ell_{i j}$ & integral length scale \\
\hline$\left\langle\sigma_{\mathrm{s}}^{2}\right\rangle$ & $\begin{array}{l}\text { second central moment of the Doppler spec- } \\
\text { trum (Doppler spectrum width) }\end{array}$ \\
\hline$\partial / \partial z$ & vertical gradient \\
\hline$\phi$ & half-opening angle \\
\hline$\rho$ & surface air density \\
\hline$\tau$ & pulse duration \\
\hline$\theta$ & azimuth angle \\
\hline$\theta_{\mathrm{T}}$ & surface potential temperature \\
\hline$\varepsilon$ & energy dissipation rate \\
\hline FWHM & full width half maximum \\
\hline PPI & plan position indicator \\
\hline RHI & range height indicator \\
\hline VAD & velocity azimuth display \\
\hline $\mathrm{C}-\mathrm{W}$ & continuous-wave \\
\hline
\end{tabular}

Acknowledgements. This work is carried out as a part of a research project funded by the Danish Ministry of Science, Innovation and Higher Education - Technology and Production, grant no. 11117018. The resources provided by the Center for Computational Wind Turbine Aerodynamics and Atmospheric Turbulence funded by the Danish Council for Strategic Research grant no. 09-067216 are also acknowledged. We also thank Erik Juul from the DTU Wind Energy department for helping with the sketches of the scanning configurations.

Edited by: G. Ehret

\section{References}

Abramowitz, M. and Stegun, I. A. (Eds.): Handbook of Mathematical Functions, 9th Edn., Dover Publications, Inc., New York, 555-566, 1965.

Angelou, N., Mann, J., Sjöholm, M., and Courtney, M.: Direct measurement of the spectral transfer function of a laser based anemometer, Rev. Sci. Instrum., 83, 033111, doi:10.1063/1.3697728, 2012.

Banakh, V. A. and Smalikho, I. N.: Determination of the turbulent energy dissipation rate from lidar sensing data, Atmos. Ocean. Optics, 10, 295-302, 1997a.

Banakh, V. A. and Smalikho, I. N.: Estimation of the turbulence energy dissipation rate from the pulsed Doppler lidar data, Atmos. Ocean. Optics, 10, 957-965, 1997b.

Banakh, V. A. and Werner, C.: Computer simulation of coherent Doppler lidar measurement of wind velocity and retrieval of turbulent wind statistics, Opt. Eng., 44, 071205, doi:10.1117/1.1955167, 2005.

Banakh, V. A., Smalikho, I. N., Köpp, F., and Werner, C.: Representativeness of wind measurements with a CW Doppler lidar in the atmospheric boundary layer, Appl. Optics, 34, 2055-2067, doi:10.1364/AO.34.002055, 1995.

Banakh, V. A., Werner, C., Kerkis, N. N., Köpp, F., and Smalikho, I. N.: Turbulence measurements with a CW Doppler lidar in the atmospheric boundary layer, Atmosp. Ocean. Optics, 8, 955-959, 1995b.

Banakh, V. A., Werner, C., Köpp, F., and Smalikho, I. N.: Measurement of turbulent energy dissipation rate with a scanning Doppler lidar, Atmos. Ocean. Optics, 9, 849-853, 1996.

Banakh, V. A., Werner, C., Köpp, F., and Smalikho, I. N.: Fluctuation spectra of wind velocity measured with a Doppler lidar, Atmos. Ocean. Optics, 10, 202-208, 1997.

Banakh, V. A., Smalikho, I. N., Köpp, F., and Werner, C.: Measurements of turbulent energy dissipation rate with a CW Doppler lidar in the atmospheric boundary layer, J. Atmos. Ocean. Tech., 16, 1044-1061, doi:10.1175/15200426(1999)016<1044:MOTEDR>2.0.CO;2, 1999.

Banakh, V. A., Smalikho, I. N., Pichugina, Y. L., and Brewer, W. A.: Representativeness of measurements of the dissipation rate of turbulence energy by scanning Doppler lidar, Atmos. Ocean Optics, 23, 48-54, doi:10.1134/S1024856010010100, 2010.

Banta, R. M., Pichugina, Y. L., and Brewer, W. A.: Turbulent velocity-variance profiles in the stable boundary layer generated by a nocturnal low-level jet, J. Atmos. Sci., 63, 2700-2719, doi:10.1175/JAS3776.1, 2006. 
Bingöl, F., Mann, J., and Foussekis, D.: Conically scanning lidar error in complex terrain, Meteorol. Z., 18, 189-195, doi:10.1127/0941-2948/2009/0368, 2009.

Branlard, E., Pedersen, A. T., Mann, J., Angelou, N., Fischer, A., Mikkelsen, T., Harris, M., Slinger, C., and Montes, B. F.: Retrieving wind statistics from average spectrum of continuouswave lidar, Atmos. Meas. Tech., 6, 1673-1683, doi:10.5194/amt6-1673-2013, 2013.

Browning, K. A. and Wexler, R.: The determination of kinematic properties of a wind field using a Doppler radar, J. Appl. Meteorol., 7, 105-113, doi:10.1175/15200450(1968)007<0105:TDOKPO>2.0.CO;2, 1968.

Burton, T., Sharpe, D., Jenkins, N., and Bossanyi, E.: Wind Energy Handbook, John Wiley and Sons, LTD, 2001.

Canadillas, B., Bégué, A., and Neumann, T.: Comparison of turbulence spectra derived from LiDAR and sonic measurements at the offshore platform FINO1, in: DEWEK 2010, 10th German Wind Energy Conference, Bremen, Germany, 2010.

Chan, P. W.: Generation of an eddy dissipation rate map at the Hong Kong international airport based on Doppler lidar data, J. Atmos. Ocean. Tech., 28, 37-49, doi:10.1175/2010JTECHA1458.1, 2011.

Cohn, S. A., Mayor, S. D., Grund, C. J., Weckwerth, T. M., and Senff, C.: The lidars in flat terrain (LIFT) experiment, B. Am. Meteorol. Soc., 79, 1329-1343, doi:10.1175/15200477(1998)079<1329:TLIFTL>2.0.CO;2, 1998.

Collier, C. G., Davies, F., Bozier, K. E., Holt, A. R., Middleton, D. R., Pearson, G. N., Siemen, S., Willetts, D. V., Upton, G. J. G., and Young, R. I.: Dual-Doppler lidar measurements for improving dispersion models, B. Am. Meteorol. Soc., 86, 825-838, doi:10.1175/BAMS-86-6-825, 2005.

Davies, F., Collier, C. G., Bozier, K. E., and Pearson, G. N.: On the accuracy of retrieved wind information from Doppler lidar observation, Q. J. Roy. Meteorol. Soc., 129, 321-334, doi:10.1256/qj.01.126, 2003.

Davies, F., Collier, C. G., Pearson, G. N., and Bozier, K. E.: Doppler lidar measurements of turbulent structure function over an urban area, J. Atmos. Ocean. Tech., 21, 753-761, doi:10.1175/15200426(2004)021<0753:DLMOTS>2.0.CO;2, 2004.

Davies, F., Collier, C. G., and Bozier, K. E.: Errors associated with dual-Doppler-lidar turbulence measurements, J. Opt. APure Appl. Op., 7, S280-S289, doi:10.1088/1464-4258/7/6/005, 2005.

Davis, J. C., Collier, C. G., Davies, F., and Bozier, K. E.: Spatial variations of sensible heat flux over an urban area measured using Doppler lidar, Meteorol. Appl., 15, 367-380, doi:10.1002/met.79, 2008.

Dors, I., McHugh, J. P., Jumper, G. Y., and Roadcap, J.: Velocity spectra and turbulence using direct detection lidar and comparison with thermosonde measurements, J. Geophys. Res., 116, D01102, doi:10.1029/2010JD014606, 2011.

Drobinski, P., Brown, R. A., Flamant, P. H., and Pelon, J.: Evidence of organized large eddies by ground-based Doppler lidar, sonic anemometer and sodar, Bound.-Lay. Meteorol., 88, 343361, doi:10.1023/A:1001167212584, 998.

Drobinski, P., Dabas, A. M., and Flamant, P. H.: Remote measurement of turbulent wind spectra by heterodyne Doppler lidar technique, J. Appl. Meteorol., 39, 2434-2451, doi:10.1175/15200450(2000)039<2434:RMOTWS>2.0.CO;2, 2000.
Drobinski, P., Carlotti, P., Newsom, R. K., Banta, R. M., Foster, R. C., and Redelsperger, J.-L.: The structure of the nearneutral atmospheric surface layer, J. Atmos. Sci., 61, 699-714, doi:10.1175/1520-0469(2004)061<0699:TSOTNA>2.0.CO;2, 2004.

Eberhard, W. L., Cupp, R. E., and Healy, K. R.: Doppler lidar measurements of profiles of turbulence and momentum flux, J. Atmos. Ocean. Tech., 6, 809-819, doi:10.1175/15200426(1989)006<0809:DLMOPO>2.0.CO;2, 1989.

Emeis, S., Harris, M., and Banta, R. M.: Boundary-layer anemometry by optical remote sensing for wind energy applications, Meteorol. Z., 16, 337-347, doi:10.1127/0941-2948/2007/0225, 2007.

Engelbart, D. A. M., Kallistratova, M., and Kouznetsov, R.: Determination of the turbulent fluxes of heat and momentum in the ABL by ground-based remote-sensing techniques (a review), Meteorol. Z., 16, 325-335, doi:10.1127/0941-2948/2007/0224, 2007.

Frehlich, R.: Coherent Doppler lidar signal covariance including wind shear and wind turbulence, Appl. Optics, 33, 6472-6481, doi:10.1364/AO.33.006472, 1994.

Frehlich, R.: Effects of wind turbulence on coherent Doppler lidar performance, J. Atmos. Ocean. Tech., 14, 54-75, doi:10.1175/1520-0426(1997)014<0054:EOWTOC>2.0.CO;2, 1997.

Frehlich, R. and Cornman, L.: Estimating spatial velocity statistics with coherent Doppler lidar, J. Atmos. Ocean. Tech., 19, 355366, doi:10.1175/1520-0426-19.3.355, 2002.

Frehlich, R. and Kelley, N.: Measurements of wind and turbulence profiles with scanning Doppler lidar for wind energy applications, IEEE J. Sel. Top. Appl., 1, 42-47, doi:10.1109/JSTARS.2008.2001758, 2008.

Frehlich, R., Hannon, S. M., and Henderson, S. W.: Performance of a $2-\mu \mathrm{m}$ coherent Doppler lidar for wind measurements, J. Atmos. Ocean. Tech., 11, 1517-1528, doi10.1175/15200426(1994)011<1517:POACDL>2.0.CO;2, 1994.

Frehlich, R., Hannon, S. M., and Henderson, S. W.: Coherent Doppler lidar measurements of wind field statistics, Bound.-Lay. Meteorol., 86, 233-256, doi:10.1023/A:1000676021745, 1998.

Frehlich, R., Meillier, Y., Jensen, M. L., Balsley, B., and Sharman, R.: Measurements of boundary layer profiles in urban environment, J. Appl. Meteorol. Clim., 45, 821-837, doi:10.1175/JAM2368.1, 2006.

Frehlich, R., Meillier, Y., and Jensen, M. L.: Measurements of boundary layer profiles with in situ sensors and Doppler lidar, J. Atmos. Ocean. Tech., 25, 1328-1340, doi:10.1175/2007JTECHA963.1, 2008.

Frisch, A. S.: On the measurement of second moments of turbulent wind velocity with a single Doppler radar over non-homogeneous terrain, Bound.-Lay. Meteorol., 54, 29-39, doi:10.1007/BF00119410, 1991.

Gal-Chen, T., Xu, M., and Eberhard, W. L.: Estimation of atmospheric boundary layer fluxes and other turbulence parameters from Doppler lidar data, J. Geophys. Res., 97, 18409-18423, doi:10.1029/91JD03174, 1992.

Gottschall, J. and Peinke, J.: How to improve the estimation of power curves for wind turbines, Environ. Res. Lett., 3, 015005 , doi:10.1088/1748-9326/3/1/015005, 2008. 
Hansen, R. S. and Pedersen, C.: All semiconductor laser doppler anemometer at $1.55 \mu \mathrm{m}$, O pt. Express, 16, 18288-18295, doi:10.1364/OE.16.018288, 2008.

Hardesty, R. M. and Darby, L. S.: Ground-based and airborne lidar, in: Encyclopedia of Hydrological Sciences, edited by: Anderson, M. G., John Wiley \& Sons, Ltd., doi:10.1002/0470848944.hsa052, 2005.

Hardesty, R. M., Korrell, J. A., and Hall, F. F.: Lidar measurement of wind velocity turbulence spectra encountered by a rotating turbine blade, Tech. Rep. DOE/RL/10236-81/1, National Oceanic and Atmospheric Administration, Boulder, CO, USA, 1982.

IEC: IEC 61400-1, Wind turbines - Part 1: Design Requirements, International Electrotechnical Commission, Geneva, Switzerland, 2005a.

IEC: IEC 61400-3, Offshore wind turbines - Part 1: Design Requirements, International Electrotechnical Commission, Geneva, Switzerland, 2005b.

Iversen, T. F. Q., Jakobsen, M. L., and Hanson, S. G.: Speckle-based three-dimensional velocity measurement using spatial filtering velocimetry, Appl. Optics, 50, 1523-1533, doi:10.1364/AO.50.001523, 2011.

Jakobsen, M. L., Iversen, T. F. Q., Yura, H. T., and Hanson, S. G.: Speckle and fringe dynamics in imaging speckle-pattern interferometry for spatial-filtering velocimetry, Appl. Optics, 50, 55775591, doi:10.1364/AO.50.005577, 2011.

Kaimal, J. C. and Finnigan, J. J.: Acquisition and processing of atmospheric boundary layer data, in: Atmospheric Boundary Layer Flows, no. 7, Oxford University Press, NY, 255-257, 1994.

Kaimal, J. C., Wyngaard, J. C., Izumi, Y., and Coté, O. R.: Spectral characteristics of surface-layer turbulence, Q. J. Roy. Meteorol. Soc., 98, 563-589, doi:10.1002/qj.49709841707, 1972.

Kaiser, K., Langreder, W., Hohlen, H., and Højstrup, J.: Turbulence correction for power curves, in: Wind Energy, Proceedings of the Euromech Colloquium, edited by: Peinke, J., Schaumann, P., and Barth, S., Springer, 159-162, 2007.

Kindler, D., Oldroyd, A., Macaskill, A., and Finch, D.: An eight month test campaign of the QinetiQ ZephIR system: preliminary results, Meteorol. Z., 16, 479-489, doi:10.1127/09412948/2007/0226, 2007.

Kristensen, L., Lenschow, D. H., Kirkegaard, P., and Courtney, M.: The spectral velocity tensor for homogeneous boundary-layer turbulence, Bound.-Lay. Meteorol., 47, 149-193, doi:10.1007/BF00122327, 1989.

Kristensen, L., Kirkegaard, P., Mann, J., Mikkelsen, T., Nielsen, M., and Sjöholm, M.: Determining the velocity fine structure by a laser anemometer with fixed orientation, Tech. Rep. Ris $\varnothing-\mathrm{R}-$ 1744(EN), Risø DTU, 2010.

Kristensen, L., Kirkegaard, P., and Mikkelsen, T.: Determining the velocity fine structure by a laser anemometer with fixed orientation, Tech. Rep. Risø-R-1762(EN), Risø DTU, 2011.

Kristensen, L., Kirkegaard, P., and Mikkelsen, T.: Determining the velocity fine structure by a laser anemometer in VAD operation, Tech. Rep. DTU Wind Energy E-0008(EN), DTU Wind Energy, Lyngby, Denmark, 2012.

Kropfli, R. A.: Single Doppler radar measurement of turbulence profiles in the convective boundary layer, J. Atmos. Ocean. Tech., 3, 305-314, doi:10.1175/15200426(1986)003<0305:SDRMOT>2.0.CO;2, 1986.
Kunkel, K. E., Eloranta, E. W., and Weinman, J. A.: Remote determination of winds, turbulence spectra and energy dissipation rates in the boundary layer from lidar measurements, J. Atmos. Sci., 37, 978-985, doi:10.1175/15200469(1980)037<0978:RDOWTS>2.0.CO;2, 1980.

Lang, S. and McKeogh, E.: Lidar and sodar measurements of wind speed and direction in upland terrain for wind energy purposes, Remote Sens., 3, 1871-1901, doi:10.3390/rs3091871, 2011.

Larsen, G. C., Madsen, H. A., Thomsen, K., and Larsen, T. J.: Wake meandering: a pragmatic approach, Wind Energy, 11, 377-395, doi:10.1002/we.267, 2008.

Lawrence, T. R., Wilson, D. J., Craven, C. E., Jones, I. P., Huffaker, R. M., and Thomson, J. A. L.: A laser velocimeter for remote wind sensing, Rev. Sci. Instrum., 43, 512-518, doi:10.1063/1.1685674, 1972.

Lenschow, D. H., Mann, J., and Kristensen, L.: How long is long enough when measuring fluxes and other turbulence statistics?, J. Atmos. Ocean. Tech., 11, 661-673, 1994.

Lenschow, D. H., Wulfmeyer, V., and Senff, C.: Measuring second- through fourth-order moments in noisy data, J. Atmos. Ocean. Tech., 17, 1330-1347, doi:10.1175/15200426(2000)017<1330:MSTFOM>2.0.CO;2, 2000.

Lhermitte, R. M.: Note on wind variability with Doppler radar, J. Atmos. Sci., 19, 343-346, doi:10.1175/15200469(1962)019<0343:NOWVWD>2.0.CO;2, 1962.

Lhermitte, R. M.: Note on the observation of small-scale atmospheric turbulence by Doppler radar techniques, Radio Sci., 4, 1241-1246, doi:10.1029/RS004i012p01241, 1969.

Lothon, M., Lenschow, D. H., and Mayor, S. D.: Coherence and scale of vertical velocity in the convective boundary layer from a Doppler lidar, Bound.-Lay. Meteorol., 121, 521-536, doi:10.1007/s10546-006-9077-1, 2006.

Lothon, M., Lenschow, D. H., and Mayor, S. D.: Doppler lidar measurements of vertical velocity spectra in the convective planetary boundary layer, Bound.-Lay. Meteorol., 132, 205-226, doi:10.1007/s10546-009-9398-y, 2009.

Mann, J.: The spatial structure of neutral atmospheric surface-layer turbulence, J. Fluid Mech., 273, 141-168, doi:10.1017/S0022112094001886, 1994.

Mann, J., Cariou, J., Courtney, M., Parmentier, R., Mikkelsen, T., Wagner, R., Lindelow, P., Sjöholm, M., and Enevoldsen, K.: Comparison of 3D turbulence measurements using three staring wind lidars and a sonic anemometer, Meteorol. Z., 18, 135-140, doi:10.1127/0941-2948/2009/0370, 2009.

Mann, J., Peña, A., Bingöl, F., Wagner, R., and Courtney, M. S.: Lidar scanning of momentum flux in and above the surface layer, J. Atmos. Ocean. Tech., 27, 792-806, doi:10.1175/2010JTECHA1389.1, 2010.

Mayor, S. D., Lenschow, D. H., Schwiesow, R. L., Mann, J., Frush, C. L., and Simon, M. K.: Validation of NCAR 10.6- $\mu \mathrm{m} \quad \mathrm{CO}_{2}$ Doppler lidar radial velocity measurements and comparison with a $915-\mathrm{MHz}$ profiler, J. Atmos. Ocean. Tech., 14, 1110-1126, doi:10.1175/15200426(1997)014<1110:VONMCD>2.0.CO;2, 1997.

Mayor, S. D., Lowe, J. P., and Mauzey, C. F.: Two-component horizontal aerosol motion vectors in the atmospheric surface layer from a cross-correlation algorithm applied to scanning elastic backscatter lidar data, J. Atmos. Ocean. Tech., 29, 1585-1602, doi:10.1175/JTECH-D-11-00225.1, 2012. 
McKay, J. A.: Modeling of direct detection Doppler wind lidar, I. The edge technique, Appl. Optics, 37, 6480-6486, doi:10.1364/AO.37.006480, 1998.

Measures, R. M.: Laser Remote Sensing: Fundamentals and Applications, Krieger Publishing Company, Malabar, Florida, 524 pp., 1984.

Mikkelsen, T., Angelou, N., Hansen, K., Sjöholm, M., Harris, M., Slinger, C., Hadley, P., Scullion, R., Ellis, G., and Vives, G.: A spinner-integrated wind lidar for enhanced wind turbine control, Wind Energy, 16, 625-643, doi:10.1002/we.1564, 2012.

O’Connor, E. J., Illingworth, A. J., Brooks, I. M., Westbrook, C. D., Hogan, R. J., Davies, F., and Brooks, B. J.: A method for estimating the turbulent kinectic energy dissipation rate from a vertically pointing Doppler lidar, and independent evaluation from balloon-borne in situ measurements, J. Atmos. Ocean. Tech., 27, 1652-1664, doi:10.1175/2010JTECHA1455.1, 2010.

Peña, A., Hasager, C. B., Gryning, S.-E., Courtney, M., Antoniou, I., and Mikkelsen, T.: Offshore wind profiling using light detection and ranging measurements, Wind Energy, 12, 105-124, doi:10.1002/we.283, 2009.

Pichugina, Y. L., Banta, R. M., Kelly, N. D., Jonkman, B. J., Tucker, S. C., Newsom, R. K., and Brewer, W. A.: Horizontal-velocity and variance measurements in the stable boundary layer using Doppler lidar: sensitivity to averaging procedures, J. Atmos. Ocean. Tech., 25, 1307-1327, doi:10.1175/2008JTECHA988.1, 2008.

Pope, S. B.: Turbulent Flows, Cambridge University Press, NY, 2000.

Rodrigo, P. J. and Pedersen, C.: Reduction of phase-induced intensity noise in a fiber-based coherent doppler lidar using polarization control, Opt. Express, 18, 5320-5327, doi:10.1364/OE.18.005320, 2008.

Rodrigo, P. J. and Pedersen, C.: Field performance of an allsemiconductor laser coherent Doppler lidar, Opt. Lett., 37, 2277 2279, doi:10.1364/OL.37.002277, 2012.

Sathe, A.: Influence of wind conditions on wind turbine loads and measurement of turbulence using lidars, Ph.D Thesis, Delft University of Technology, Delft, 2012.

Sathe, A. and Mann, J.: Measurement of turbulence spectra using scanning pulsed wind lidars, J. Geophys. Res., 117, D01201, doi:10.1029/2011JD016786, 2012.

Sathe, A., Gryning, S.-E., and Peña, A.: Comparison of the atmospheric stability and wind profiles at two wind farm sites over a long marine fetch in the North Sea, Wind Energy, 14, 767-780, doi:10.1002/we.456, 2011a.

Sathe, A., Mann, J., Gottschall, J., and Courtney, M. S.: Can wind lidars measure turbulence?, J. Atmos. Ocean. Tech., 28, 853-868, doi:10.1175/JTECH-D-10-05004.1, 2011b.

Sathe, A., Mann, J., Barlas, T., Bierbooms, W. A. A. M., and van Bussel, G. J. W.: Influence of atmospheric stability on wind turbine loads, Wind Energy, doi:10.1002/we.1528, in press, 2012.

Schlipf, D., Schlipf, D. J., and Kühn, M.: Nonlinear model predictive control of wind turbines using LIDAR, Wind Energy, doi:10.1002/we.1533, in press, 2012.

Seibert, P., Beyrich, F., Gryning, S.-E., Joffre, S., Rasmussen, A., and Tercier, P.: Review and Intercomparison of Operational Methods for the Determination of the Mixing Height, Atmos. Environ., 34, 1001-1027, 2000.
Sela, N. and Tsadka, S.: System for monitoring wind characteristics to install wind turbines for generating electricity, has data processing subsystem for receiving data from laser anemometers and providing output data that represents wind characteristics, Patent no. WO2011036553-A1, 2011.

Simley, E., Pao, L. Y., Frehlich, R., Jonkman, B., and Kelley, N.: Analysis of light detection and ranging wind speed measurements for wind turbine control, Wind Energy, doi:10.1002/we.1584, in press, 2013.

Sjöholm, M., Mikkelsen, T., Mann, J., Enevoldsen, K., and Courtney, M.: Spatial averaging-effects on turbulence measured by a continuous-wave coherent lidar, Meteorol. Z., 18, 281-287, doi:10.1127/0941-2948/2009/0379, 2009.

Smalikho, I., Kopp, F., and Rahm, S.: Measurement of atmospheric turbulence by $2-\mu \mathrm{m}$ Doppler lidar, J. Atmos. Ocean. Tech., 22, 1733-1747, doi:10.1175/JTECH1815.1, 2005.

Smalikho, I. N.: On measurement of dissipation rate of the turbulent energy with a CW Doppler lidar, Atmos. Ocean. Optics, 8, 788793, 1995.

Smith, D. A., Harris, M., Coffey, A. S., Mikkelsen, T., Jørgensen, H. E., Mann, J., and Danielian, R.: Wind lidar evaluation at the danish wind test site in Høvsøre, Wind Energy, 9, 87-93, doi:10.1002/we.193, 2006.

Sonnenschein, C. M. and Horrigan, F. A.: Signal-to-noise relationships for coaxial systems that heterodyne backscatter from atmosphere, Appl. Optics, 10, 1600, doi:10.1364/AO.10.001600, 1971.

Taylor, G. I.: The spectrum of Turbulence, P. Roy. Soc. Lond. A, 164, 476-490, 1938.

Tucker, S. C., Brewer, W. A., Banta, R. M., Senff, C. J., Sandberg, S. P., Law, D. C., Weickmann, M., and Hardesty, R. M.: Doppler lidar estimation of mixing height using turbulence, shear and aerosol profiles, J. Atmos. Ocean. Tech., 26, 673-688, doi:10.1175/2008JTECHA1157.1, 2009.

von Kármán, T.: Progress in the statistical theory of turbulence, P. Natl. Acad. Sci. USA, 34, 530-539, 1948.

Wagner, R., Mikkelsen, T., and Courtney, M.: Investigation of turbulence measurements with a continuous wave, conically scanning LiDAR, Tech. Rep. Ris $\varnothing-R-1682(E N)$, Ris $\varnothing$ DTU, 2009.

Wagner, R., Courtney, M., Gottschall, J., and LindelöwMarsden, P.: Accounting for the speed shear in wind turbine power performance measurement, Wind Energy, 14, 993-1004, doi:10.1002/we.509, 2011.

Wilczak, J. M., Gossard, E. E., Neff, W. D., and Eberhard, W. L.: Ground-based remote sensing of the atmospheric boundary layer: 25 years of progress, Bound.-Lay. Meteorol., 78, 321-349, doi:10.1007/BF00120940, 1996.

Wilson, D. A.: Doppler Radar Studies of Boundary Layer Wind Profiles and Turbulence in Snow Conditions, in: Proc. 14th Conference on Radar Meteorology, Tucson, USA, 191-196, 1970.

Wyngaard, J. C.: Turbulence in the Atmosphere, Cambridge University Press, NY, 2010.

Wyngaard, J. C. and Coté, O. R.: The budgets of turbulence kinetic energy and temperature variance in the atmospheric surface layer, J. Atmos. Sci., 28, 190-201, doi:10.1175/15200469(1971)028<0190:TBOTKE>2.0.CO;2, 1971.

Xia, H., Sun, D., Yang, Y., Shen, F., Dong, J., and Koboyashi, T.: Fabry-perot interferometer based mie doppler lidar for low 
tropospheric wind observation, Appl. Optics, 46, 7120-7131, doi:10.1364/AO.46.007120, 2007. 